\title{
Information Acquisition and Exchange in
}

\section{Social Networks}

\author{
Sanjeev Goyal* \\ Stephanie Rosenkranz \\ Utz Weitzel \\ Vincent Buskens
}

March 28, 2016

\begin{abstract}
A central feature of social networks is information sharing. The Internet and related computing technologies shape the relative costs of private information acquisition and forming links with others. This paper presents an experiment on the effects of changing costs.

We find that a decline in relative costs of linking makes private investments more dispersed and gives rise to denser social networks.
\end{abstract}

${ }^{*}$ Corresponding author: Faculty of Economics and Christ's College, University of Cambridge. Email: sg472@cam.ac.uk

We are grateful to the Editor, Martin Cripps, and three anonymous referees for comments that have significantly improved the paper. We also thank Nicolas Carayol, Syngjoo Choi, Matthew Elliott, Edoardo Gallo, Ben Golub, Friederike Mengel, Francesco Nava, Romans Pancs, Pauline Rutsaert, Vessela Daskalova and seminar participants at ASSET 2012, Stockholm, ESA 2012, Cologne, Bordeaux, Cambridge, Rotterdam and Cape Town for helpful comments. The paper was circulated as a working paper in 2012 with the title "Individual search and social communication". 
Aggregate investment falls, but individuals' access to investment remains stable, due to increased networking. The overall effect is an increase in individual utility and aggregate welfare.

Individuals (and organizations) acquire information privately and by forming communication links with others. Private acquisition of information is costly; similarly, creating and maintaining personal contacts takes time and resources. The development of modern information technology creates a platform for extensive on-line social engagement: it has a major impact on the relative cost of these two ways of accessing information. The goal of this paper is to empirically study the economic effects of this change. ${ }^{1}$

We use laboratory experiments to study this trade-off as they allow us to control the main variables directly: the costs and benefits of linking and of individual public good provision. We can study causal determinants of the processes at work. Moreover, we can measure the provision of the public good and the welfare implications explicitly.

The theoretical framework for our experiment is taken from Galeotti and Goyal (2010). In their model, individuals choose a level of investment given by $x_{i}$, and the number of links with others, given by $\eta_{i}$. Investments take on a general form and are naturally interpreted as a local public good. ${ }^{2}$ Indi-

\footnotetext{
${ }^{1}$ For a wide ranging overview of the economics of modern information technology, see Peitz and Waldfogel (2012). For a study of information flows and their impact on interfirm collaboration links, see Frankort et al. (2012).

${ }^{2}$ This framework combines an approach to network formation introduced in Goyal (1993) and Bala and Goyal (2000) with a model of local public good provision in fixed networks taken from Bramoullé and Kranton (2007).
} 
vidual investment is costly: each unit of investment $\operatorname{costs} c>0$. Similarly, linking activity is costly: each link costs $k>0$. Furthermore, investment activity of different individuals is substitutable: the marginal utility of own investment is falling in the investment level of connected others. Define $\hat{y}$ as the investment an isolated individual would make.

Galeotti and Goyal (2010) show that every (strict) Nash equilibrium of this game is characterized by investment sharing. The theory yields sharp predictions on some dimensions: every individual must access $\hat{y}$ investment (own investment and investment from others) and total investment by society must also be equal to $\hat{y}$, independently of the linking costs. The theory is permissive on other dimensions: a variety of networks and distribution of individual investments levels can be sustained in equilibrium. For instance, at low costs of linking, there exists an equilibrium with a single hub player acquiring $\hat{y}$ and all other players forming links to him/her. But there is another equilibrium in which all players make investments and are fully connected with each other. On the other hand, at high costs of linking, only the single hub outcome is sustainable in equilibrium. One of the main questions of interest is the impact of changing linking costs on welfare. It is easy to see that welfare impact depends crucially on which equilibrium is played at low costs. Roughly speaking, the welfare improvements are larger if the single hub equilibrium is played across the different linking costs, but are muted if the multiple hub equilibrium is played at low costs. ${ }^{3}$ This multiplicity in

\footnotetext{
${ }^{3}$ We note that equilibrium total investment is constant across linking costs, but that
} 
equilibrium outcomes is thus an important motivation for our experimental work.

We conduct a range of experiments with groups of four subjects. To accommodate the complexity of the strategic structure of the game and to give players ample opportunities for learning we run the experiment in continuous time. Subjects can make choices and revise them over time and we have a random termination time.

We start with homogenous costs of investment, $c$, and low costs for links, $k$. We then compute the level of $\hat{y}$. In the experiment, we find that all subjects indeed have access to $\hat{y}$ units of investment. Total investment in society is much lower than $4 \times \hat{y}$ : so there is extensive sharing of investments. In line with theory, individual investments and the number of in-coming links are positively correlated.

We then turn to the effects of changing costs of linking. As we raise linking costs, the theory predicts that investment accessed and aggregate investment remains unchanged at $\hat{y}$. However, at a higher linking cost, a person must obtain more investment for the link to be justified. Given that total investment is constant (across linking costs), this implies that the low cost equilibrium with many hubs and multiple links can no longer be sustained. Thus, the maximal number of hubs (and correspondingly the number of links) is falling in costs of linking. In the experiment, subjects access $\hat{y}$ at the number of links vary from $n-1$ (in the hub-spoke (star) network) all the way to $n(n-1) / 2$ (in the fully connected (complete) network). 
all cost levels. But they coordinate on multiple-hubs at low linking costs and the number of hubs falls with rising linking costs. In line with the theory, hubs make larger investment as linking costs rise.

Next we consider a setting with heterogeneity in costs of investment. The low-cost player $i$ 's stand-alone optimal investment is $\hat{y}_{1}>\hat{y}$. The unique equilibrium network has the star architecture with the low-cost player as the hub, independently of the linking costs. In the experiment we randomly determined one player in each group to have lower costs. We see that this low-cost player is more likely to be the hub and that individuals access $\hat{y}_{1}$ units of investment on average, at all cost levels. The macroscopic patterns with regard to linking costs exhibit the same pattern as in the homogenous treatments: the number of hubs and links fall as we raise linking costs, while average investment by hubs rises.

One important prediction of the theory, in both the homogenous and the heterogeneous cost treatments, is that aggregate investment is invariant with respect to linking costs. In the experiment, we find that aggregate investment is higher than predicted and that it increases with linking costs. We develop an explanation for these two departures from the theory. The first point to note is that in the original model of Galeotti and Goyal (2010), players make their choices simultaneously. By contrast, in the experiment, players make choices sequentially and repeatedly, and there is an uncertain end point. We focus on this difference: the main idea we explore is that, toward the end of the game, players explore small and local moves to improve their payoffs. A 
strategy profile is said to be stable if there exists no small and local deviation that is profitable, in this sense.

An important feature of the equilibrium outcome in the static game is that the hub player makes large investments while the peripheral nodes make zero investments and form links with the hub. In a dynamic setting, the hub can shade his investment downward, in anticipation of a potential upward shift in the investment by the peripheral player. The extent of downward shading is constrained by the threat of a link deletion by peripheral player. Our analysis explores the bounds on the shading and the level of investments by the peripheral players. We note that in this situation, the peripheral player will choose an investment level that is optimal given the hub's investment choice (so investment accessed by the peripheral player must be $\hat{y}$ ). On the other hand, as the hub potentially has access to multiple peripheral players, he/she accesses investment in excess of the static equilibrium level $\hat{y}$. This explains our finding that, contraty to the theoretical prediction, hubs earn more than peripheral players, and it provides an account for higher than static equilibrium investments in the experiment. Building on these considerations, we also show that higher costs of linking imply higher aggregate investments.

The final major finding concerns welfare. In the homogenous cost case (when all players have the same costs of investment), at high linking costs, there is a unique equilibrium with a single hub. However, at lower linking costs in addition to the single hub outcome, there also exist other equilibrium outcomes, with multiple hubs and more links. So the theoretical predictions 
on individual and aggregate welfare are a priori ambiguous. The data from the experiment yields two clear-cut findings. Aggregate earnings are below the (least efficient) Nash equilibrium prediction in all cases. Moreover, they are falling in linking costs. ${ }^{4}$ While welfare is falling in linking costs, this fall is muted. The reason for this is that subjects coordinate on the multiplelink and dense networks at low costs of linking. This means that aggregate welfare at these low costs is much lower than what is potentially attainable. The fall in welfare due to rising linking costs is correspondingly smaller. ${ }^{5}$

To summarize, our experimental subjects behave in line with the predictions of the theory with regard to investment accessed by an individual player and on the presence of significant linking and investment sharing. The experiment, however, goes beyond the theory in one important dimension: it shows that as linking costs fall, investment is more dispersed and it is accompanied by denser social networks. This has interesting and large effects on welfare. Finally, the experiment also yields an important departure from the theory: aggregate investment is sensitive to costs of linking.

Our paper is a contribution to the literature on public goods and networks. In the literature on public goods experiments, an important general finding is that individuals contribute more than what theory predicts though they contribute less than the first best; for surveys, see Ledyard (1995), Cro-

\footnotetext{
${ }^{4}$ We observe very similar patterns with regard to welfare in the heterogeneous cost treatments.

${ }^{5}$ This finding may be of interest for the study of on-line social activity: low linking costs create the potential for a greater diffusion in public good provision and a corresponding increase in linking activity.
} 
son (2010), and Holt and Laury (2012). Thus individual utility is generally higher than the Nash equilibrium level. The principal novelty in the present paper is that individual choices determine whether their actions and others' actions become public goods or remain 'private'. This is accomplished through the formation of links. The experiment reveals that this 'endogeneity' of public goods has important implications for behavior and welfare. With increasing linking costs the aggregate investment in the 'public' good rises, but due to lesser linking, every individual has access to the same amount of it. Moreover, in all treatments, endogeneity of links leads to outcomes that are worse than the worst Nash equilibrium (in terms of aggregate welfare).

Our paper is also a contribution to the study of social networks. There is now a large theoretical literature on social networks but the empirical assessment of networks in economic activity remains a challenge. This motivates the recent experiments on networks (Charness et al., 2007; Cassar, 2007; Callander and Plott, 2005; Burger and Buskens, 2009; Goeree et al., 2009; Falk and Kosfeld, 2012; Rosenkranz and Weitzel, 2012; Charness et al., 2014; and Van Dolder and Buskens, 2014). This work considers either games on fixed networks or pure network formation games. The novelty in the present paper is that we combine both activities and focus on the trade-off between private investments and linking activity. Two recent papers, Rong and Houser (2012) and Leeuwen et al. (2013) also report experiments on the Galeotti and Goyal (2010) paper. The distinctive feature of our paper is the focus on the relative costs of social linking and the empirical findings relating 
to the large economic effects of such changes.

The rest of the paper is organized as follows: Section 2 describes the theoretical model. Section 3 presents the experimental design. Section 4 presents and discusses the experimental findings. Section 5 concludes.

\section{The network game}

The following model is taken from Galeotti and Goyal (2010). Suppose there is a set of agents $N=\{1,2, \ldots, n\}$ with $n \geq 3$ and let $i$ and $j$ be members of this set. Let each player $i$ choose $x_{i} \in X$ with $X \in[0, \bar{X}]$ (denoting agent $i$ 's effort level on the production of a local public good, and a set of links represented as a vector $g_{i}=\left(g_{i 1}, \ldots, g_{i i-1}, g_{i i+1} \ldots, g_{i n}\right)$, where $g_{i j} \in\{0,1\}$, for each $j \in N \backslash\{i\}$. If $g_{i j}=1$, agent $j$ has a link with player $i$ and benefits directly from agent $i$ 's effort, and $g_{i j}=0$ otherwise. Suppose that $g_{i} \in G_{i}=\{0,1\}^{n-1}$.

The set of strategies of player $i$ is denoted by $S_{i}=X \times G_{i}$. Let $S=$ $S_{1} \times \ldots \times S_{n}$ to be the set of strategies of all players. A strategy profile $s=$ $(x, g) \in S$ specifies the investment made by each player, $x=\left(x_{1}, x_{2}, \ldots, x_{n}\right)$, and the network of links $g=\left(g_{1}, g_{2}, \ldots, g_{n}\right)$. The network of links $g$ is a directed graph; let $G$ be the set of all possible directed graphs on $n$ vertices.

Define $N_{i}(g)=\left\{j \in N: g_{i j}=1\right\}$ as the set of players with whom $i$ has formed a link, and let $\eta_{i}(g)=\left|N_{i}(g)\right|$, the number of links formed by $i$. The closure of $g$ is an undirected network denoted $\bar{g}=c l(g)$ where 
$\bar{g}_{i j}=\max \left\{g_{i j}, g_{j i}\right\}$ for each $i$ and $j$ in $N$, reflecting the bilateral nature of exchange between two players. Define $N_{i}(\bar{g})=\left\{j \in N: \bar{g}_{\hat{\imath} j}=1\right\}$ as the set of players directly connected to $i$.

The core-periphery network plays a prominent role in our analysis. We now define it formally: There are two groups of players, $\hat{N}_{1}(\overline{\mathbf{g}})$ and $\hat{N}_{2}(\overline{\mathbf{g}})$, with the feature that $N_{i}(\overline{\mathbf{g}})=\hat{N}_{2}(\overline{\mathbf{g}})$ for all $i \in \hat{N}_{1}(\overline{\mathbf{g}})$, and $N_{j}(\overline{\mathbf{g}})=N \backslash\{j\}$ for all $j \in \hat{N}_{2}(\overline{\mathbf{g}})$. We will refer to nodes which have $n-1$ links as as hubs, while we will refer to the complementary set of nodes as peripheral nodes or as spokes.

The payoff to player $i$ under strategy profile $s=(x, g)$ is:

$$
\Pi_{i}(s, g)=f\left(x_{i}+\sum_{j \in N_{i}(\bar{g})} x_{j}\right)-c x_{i}-\eta_{i}(g) k
$$

Costs of investment are represented by $c>0$, while linking costs are represented by $k>0$. The payoff function represents the tradeoff described in the introduction and the local public good character of private investment. The benefit $f(y)$ of a player depends on the aggregate investment by her direct neighbors, which is not necessarily identical to the aggregate investment available in the network.

For the experiment we assume that $f(y)$ is twice continuously differentiable, increasing, and strictly concave in $y$, and that $f(0)=0, f^{\prime}(0)>c$ and $f^{\prime}(\bar{X})=z<c$. Under these assumptions there exists a number $\widehat{y} \in(0, \bar{X})$, such that $\widehat{y}=\arg \max _{y \in X} f(y)-c y$. 
Define $I(s)=\left\{i \in N \mid x_{i}>0\right\}$ as the set of players who make positive investments. Galeotti and Goyal (2010) prove:

Proposition 1 Suppose payoffs are given by (3) and $k<c \widehat{y}$. In every strict equilibrium $s=(x, g)$ : (1.) $\sum_{i \in N} x_{i}=\hat{y}$, and (2.) the network has a core-periphery architecture. Hubs make positive investments and peripheral players make no investments.

They show that as the relative linking costs $k / c$ grow, the number of hubs decreases, each hub player makes larger investments, and the total number of links decreases. In particular, if $k / c \in(\widehat{y} / 2, \widehat{y})$, then there is only one hub, and the communication structure takes the form of a periphery sponsored star. Note that in every strict equilibrium aggregate investment will be equal to $\hat{y}$ and is thus independent of the level of linking costs.

Suppose that there exists a small heterogeneity in costs of investment. Let $c_{i}=c$ for all $i \neq 1$ and $c_{1}=c-\epsilon$, where $\epsilon>0$. Define $\widehat{y}_{1}=$ $\arg \max _{y_{1} \in X} f\left(y_{1}\right)-c_{1} y$. Proposition 3 of Galeotti and Goyal (2010) establish:

Proposition 2 Suppose that $k<f\left(\widehat{y}_{1}\right)-f(\widehat{y})+c \hat{y}^{6}{ }^{6} \quad$ In every strict equilibrium $s^{*}=\left(g^{*}, x^{*}\right)$, (i) $\sum_{i \in N} x_{i}^{*}=\widehat{y}_{1}$ (ii) the network is a peripherysponsored star with player 1 as hub, and (iii) either $x_{1}^{*}=\widehat{y}_{1}$ and $x_{i}^{*}=0$, for all $i \neq 1$, OR $x_{1}^{*}=\left((n-1) \widehat{y}-\widehat{y}_{1}\right) /(n-2)$, and $x_{i}=\left(\widehat{y}_{1}-\widehat{y}\right)(n-2)$, for all, $i \neq 1$.

\footnotetext{
${ }^{6}$ The inequality gives us the upper bound on the cost of a link for a high cost player to link with a low cost hub player.
} 
Observe that a slight cost heterogeneity leads to the low-cost player becoming the unique hub player; this illustrates the power of strategic reasoning in shaping networks and behavior.

\section{The experimental design and hypotheses}

In the experiment, subjects faced the decision problem characterized above: groups of $N=4$ subjects chose a level of investment and, simultaneously, they chose to which other players they wanted to be connected. The payoff is given by the following function (with $\bar{X}=29$ ): ${ }^{7}$

$$
\pi_{i}=\left(x_{i}+\sum_{j \in N(i ; \bar{g})} x_{j}\right)\left(29-\left(x_{i}+\sum_{j \in N(i ; \bar{g})} x_{j}\right)\right)-c_{i} x_{i}-\eta_{i}(g) k .
$$

This implies that (given the network) the optimal effort level $x_{i}$ for a player $i$ is:

$$
x_{i}=\left(29-c_{i}\right) / 2-\sum_{j \in N(i ; \bar{g})} x_{j} .
$$

Our design consists of two treatment variables: the linking costs $k$, and the $\operatorname{costs} c_{i}$ for investment. In the experiment, investments were constrained to integers. Table 1 presents our treatments, which we label by roman numbers in the following.

- Insert Table 1 here -

\footnotetext{
${ }^{7}$ For investments larger than the optimal level the function increased linearly.
} 


\section{The baseline treatment}

In the baseline treatment, we set $c=5$ and $k=10$. For these values $\widehat{y}=12$, and the parameters satisfy $k<c \widehat{y}$. We refer to this as Treatment I.

Appendix A provides a proof that in every equilibrium the sum of total investments is equal to $12 .{ }^{8}$ With this result on aggregate investment being equal to $\hat{y}=12$, we then apply Proposition 1 in Galeotti and Goyal (2010) to provide a complete characterization of equilibria. Figure 1 presents the key features of equilibrium outcomes.

— Insert Figure 1 here -

There are multiple equilibria possible but they share some key macroscopic properties: there is investment sharing in all of them, every individual accesses 12 units of investment, and aggregate investment in society is also 12. There is positive correlation between level of individual investment and the number of others who link with this person (her in-degree). Theory also predicts individual earnings to vary greatly within an equilibrium and also across equilibria. Finally, aggregate earnings are predicted to also vary greatly across equilibria (see Table 3 ).

\section{Linking costs}

\footnotetext{
${ }^{8}$ The original results of Galeotti and Goyal (2010) apply to strict Nash equilibrium. In our experimental treatments we assume that investments take on integer values only and this restriction allows us to draw stronger implications and show that aggregate investment is equal to $\hat{y}=12$ in every equilibrium (and not just in the strict equilibrium).
} 
A key aspect of the model is the comparison of linking costs and the costs of investment. To explore the role of this comparison we vary the linking costs. We raise the costs from $k=10$ to $k=24$ and then to $k=36$; we refer to these as Treatments II and III. Figure 1 provides a characterization of equilibrium outcomes. In Treatment II, with $k=24$, an equilibrium contains either 1 hub with 3 links or 2 hubs with 4 links. Investment by a hub must be at least 4.8 to justify linking by peripheral players. In Treatment III, with $k=36$, an equilibrium contains 1 hub and 3 links. Investment by the hub must exceed 7.2. Across these cost levels, individuals access exactly $\widehat{y}=12$ units of investment and aggregate investment remains at 12 . For easy reference all equilibrium values including earnings are presented in Table 3.

These observations yield our first hypothesis on the comparisons across Treatment I, II and III.

Hypothesis 1: With homogenous costs of investment an increase in linking costs (a) reduces the number of hubs, (b) raises investments by hubs, and (c) reduces the number of links, while (d) individually accessed as well as aggregate investment remains unchanged, and (e) aggregate earnings fall.

\section{Heterogeneity in costs of investment}

To understand the importance of heterogeneity among players for the emergence of core-periphery structures, we consider the role of heterogeneity in costs for investment across individuals. Suppose $c_{i}=5$ for all $i \neq 1$ and $c_{1}=c-\epsilon$, where $\epsilon=2$. We allow for the same three levels of linking costs 
as in the homogeneous treatments, i.e. $k=\{10,24,36\}$. We refer to these heterogeneous treatments as Treatments IV-VI. It follows that the low-cost player's stand-alone optimal investment is $\widehat{y}_{1}=13$. Moreover, $k<f\left(\widehat{y}_{1}\right)-$ $f(\widehat{y})+c \widehat{y}$, which in combination with the discrete action space implies that the unique equilibrium network is a periphery-sponsored star and the low-cost player is the hub, investing $\widehat{y}_{1}$, irrespective of the linking costs. The proof of this property is presented in Appendix A. Figure 1 provides a characterization of equilibrium outcomes. Our second hypothesis operationalises Proposition 2 and refers to a comparison between Treatment I and IV $(k=10){ }^{9}$

HyPOTHESIS 2: If linking costs are low $(k=10)$, heterogeneity with respect to costs of investment specialization: (a) the low-cost player is the hub. Moreover, heterogeneity (b) reduces the number of hubs, (c) raises investment by hubs, and (d) lowers the number of links, and (e) raises aggregate investment.

Note that part (e) is a direct consequence of the fact that with heterogeneous players the low-cost player is the unique hub whose optimal investment, which is identical to aggregate investment, is larger due to his lower costs.

\footnotetext{
${ }^{9}$ For Hypothesis 2, we focus on the benchmark cost $k=10$; in other words, we compare treatment I and IV. This comparison that offers the greatest contrast: with homogenous costs networks with 1-4 hubs may arise in equilibrium while there is a network with a unique hub in the heterogeneous costs case. For higher links costs, the impact of cost heterogeneity is much smaller.
} 


\subsection{Experimental procedures}

The computerized experiment was designed using the software program ztree (Fischbacher, 2007) and conducted in the Experimental Laboratory for Sociology and Economics (ELSE) at Utrecht University. In total, eight experimental sessions of approximately one-and-a-half hours were scheduled and completed. Before the start of every experiment, general written instructions were given, which were kept identical across sessions (see Appendix B).

Using the ORSEE recruitment system (Greiner, 2004), over 1000 potential subjects from pool of the ELSE lab at Utrecht University, consisting mainly of students, were approached by e-mail to participate in the experiment. A total of 152 subjects (either 16 or 20 per session) participated. Each subject played 24 rounds of a local public goods game with linking decisions. Subjects were informed about the fact that at the beginning of each round, they were randomly allocated to a group together with three other participants. This resulted in 152/4 = 38 observations at the group level per round. Subjects were indicated as circles on the screen and could identify themselves by color: each subject saw him- or herself as a blue circle while all other members of the same group were represented as black circles (see screen shots in Appendix B). In the heterogeneous treatments the low-cost player was determined randomly at the beginning of each round and on the screen this player was marked with an additional square. Subjects could see investment levels and links as well as profits of all other players all the time. The identity of the subjects was not identifiable between different rounds or 
at the end of the experiment. ${ }^{10}$

In each session we ran every treatment. The order of the treatments was balanced across sessions. ${ }^{11}$ Each of the six treatments I - VI described in the previous section was played for 4 rounds: 1 trial round and 3 payment rounds. As we did not use the data of the trial round in our analysis, this ultimately led to 114 (=38 groups $\times 3$ rounds) observations at the group level per treatment. Moreover, we obtained $456(=38$ groups $\times 3$ payed rounds $\times 4$ players) observations at an individual level.

Every round had the same structure and lasted between 105 and 135 seconds (on average 120.5 seconds). This was communicated to subjects at the start of the experiment and again at the point of 105 seconds. Starting from a situation with no investments and no links, subjects indicated simultaneously on their computer terminals (by clicking on one of two buttons at the bottom of the screen) how much (expressed in "points") they wished to invest. By clicking on one of the circles on the screen representing another participant, subjects could link to this other participant. A one-headed arrow appeared to indicate the link and its direction. By clicking again on the other participant the arrow and, thus, the link was removed again. The participant who initiated this link had to pay some points for this link. If both participants had clicked for a specific link a two-headed arrow appeared and both participants needed to pay points for this link.

\footnotetext{
${ }^{10}$ The aim of this allocation mechanism is to minimize the dependence across observations (Falk and Kosfeld, 2012).

${ }^{11}$ See Table B.1 in Appendix B for the sequence of the treatments.
} 
We note that, during the experiment, full information about the investments and linking decisions of all other subjects was continuously provided. Also, resulting payoffs of all participants could continuously be observed on the screen. At the end of each round, subjects were informed about the number of points earned with the investments and links as were on the screen at the end of that round. In other words, subject earnings only depended on the situation at the (random) end of every round.

It is important to clarify some aspects of the experimental design.

Our first remark concerns the complexity of the game and the need for trial time: Experience with previous experiments on network formation suggests that individuals find the decision problem to be very complex and this inhibits behavior (Goeree et al., 2009; Falk and Kosfeld, 2012). Subjects appear to need time to understand the game and to coordinate their actions. We address this issue in our design by having a trial round (non-payoff relevant) at the beginning of each treatment, and, in addition, by starting each round with a trial period of 105 seconds where actions do not have direct payoff implications. Moreover, to facilitate activity, we allowed subjects to choose links and investment levels in continuous time.

Our second remark concerns the end of the time interval between 105 and 135 seconds: while a random end may induce players in a disadvantageous equilibrium position to try to move play towards a more advantageous equilibrium if the interval is still long enough, a fixed end may turn the game into an unpredictable waiting game in which players are likely to mis-coordinate 
during the final stage. After an internal test session we considered the second effect to be more severe.

The third set of remarks is about the relation between the theoretical model discussed in Section 2, and the experimental design.

A general observation is that design departs in many ways from the static model studied by Galeotti and Goyal (2010). This departure was in some cases motivated by considerations of complexity of the game, as discussed above. But it is important to emphasize a more general methodological point: our goal in this paper is to examine the economic implications of the trade-off between costs of linking and the costs of personal investment as alternative routes to being well informed. Our view is that if the tradeoffs identified in the theoretical paper are robust then they should also be reflected in an experimental design that departs in some dimensions from the static model. With this general observation in place, we now take up some more specific points.

We may consider our experimental design as a sequence of simultaneous move games, with a stochastic end stage, and only the last stage behavior to be payoff relevant. In such an interpretation, it follows from standard arguments that any equilibrium of the stage game can be implemented in the stage game of our experiment.

Players know that activity in the first 105 seconds has no (direct) payoff relevance: actions in this period may therefore be viewed as 'cheap talk'. This raises the question of whether this cheap talk can select between different 
equilibria of the stage game. There is a large literature on this subject: a general message is that cheap talk is more likely to be effective in equilibrium selection if equilibria are Pareto ranked (see e.g., Farrell and Rabin (1996)). In our setting, equilibria are not Pareto ranked. So we believe that cheap talk is not helpful in selecting equilibria in our analysis.

The final remark is about the potential repeated game effects. The period from 105 seconds until the end of the game may be viewed as a type of 'repeated game', with an ending that is stochastic with a well defined finite end point (at 135 seconds). From the work of Benoît and Krishna (1985), we know that repetition may be used to select among different stage game equilibrium and indeed even go beyond stage game equilibrium - to Pareto improving profiles of actions. This is certainly a possibility in our experimental design. We come back to this issue in Section 4.3. below. ${ }^{12}$

At the end of the experiment, points were converted to Euros at a rate of 200 points $=$ Euro 1. The total was then rounded upwards to Euro 0.5. On average, the experiment lasted 80 minutes and subjects earned Euro 14.40. At the end of the experiment, subjects were asked to fill in a short questionnaire about their demographic profiles.

\footnotetext{
${ }^{12}$ There is also the possibility that once play settles on a stage game equilibrium a player who is disadvantaged (such as the hub) may choose to signal a move to a different stage game equilibrium though a deviation in personal investment. While this dynamic might be at work we believe that our main results, which pertain to the effects of falling linking costs, are robust to this dynamic as it is common across all our treatments.
} 


\section{Experimental findings}

\subsection{Description of sample and variables}

Table 2 describes the sample across all sessions and treatments. ${ }^{13}$ On average, a subject contributed 4.4 units, invested in 1.03 links to other players (outdegree) and had 1.03 other players linking to her (in-degree). On average, a period lasted 120.5 seconds during which a subject took 24.7 linking decisions and 52 investment decisions (i.e. they clicked the respective buttons 24.7 and 52 times, respectively). Thus, the experiment was characterized by high level of activity in both investment and linking decisions.

- Insert Table 2 here -

Table 3 provides a summary of investments and linking per treatment, and reports profits at the individual and at the group level. In the following subsection, we use these variables and the differences between treatments, and report the relevant statistical analyses to test our hypotheses. ${ }^{14}$

— Insert Table 3 here -

With respect to individual investment, Table 3 shows that in line with theory the median player accesses exactly 12 units of investment, while the

\footnotetext{
${ }^{13}$ Approximately $65 \%$ of the 152 subjects participating in the experiment were female and $62 \%$ were Dutch. On average, a subject knew 0.7 other people in the lab by first name ('friends'), and was 21.3 years old.

${ }^{14}$ In this paper, we use $t$-tests for the comparison of averages, Wilcoxon rank-sum (MannWhitney) tests for the equality of medians, and Kolmogorov-Smirnov tests for the equality of distribution functions. Where applicable, all statistical significance tests are two-tailed unless reported otherwise. Treatments V and VI are robustness checks for Treatment IV.
} 
average access is 12.69 units. Although this average access is statistically different from $\widehat{y}=12$ (t-test, $p<0.01)$, its deviation is less than 1 unit from the predicted value, which was the minimum increment in the experiment. Also for the heterogeneous treatments, in line with theory we observe that individuals, in the median, access 13 units of investment regardless of the level of linking costs. ${ }^{15}$ For the average we also find that it is statistically not different from the theoretically predicted value of $\widehat{y}_{1}=13$ ( $t$-test, $p=0.229$, in Treatment IV). In Table 3, we observe for the baseline Treatment I, a mean total investment per group of 15.18 units, which is significantly higher than the theoretically predicted level of $\widehat{y}=12 .{ }^{16}$ Figure 2 presents the distribution of investments accessed in Treatments I and IV.

\section{- Insert Figure 2 here -}

While total investment in society is larger than predicted, it still is much lower than 48 units, the level that would prevail if every individual would choose its optimal level independently. As each individual, on average, has access to approximately 12 units of investment, this means that there is considerable sharing of investment among individuals.

This insight is confirmed by an analysis of the relation between an individual's investment and her in-degree, i.e. the number of directed, incoming

\footnotetext{
${ }^{15}$ Wilcoxon rank-sum tests show that the accessed levels of investment for $k=24$ and $k=36$ do not differ significantly $(z=0.455)$ and only at $z=0.093$ for $k=10$ and $k=24$. With $t$-tests we find a similar pattern with a $p=0.438$ for $k=24$ versus $k=36$, and $p=0.002$ for $k=10$ versus $k=24$.

${ }^{16}$ Our statistical tests ( $t$-test, Wilcoxon rank-sum, Kolmogorov-Smirnov) confirm that aggregate investment is higher than 12 at the $1 \%$ level of statistical significance.
} 
links from other individuals. Figure 3 presents a box plot on this relation, i.e. the average node investment per node in-degree (x-axis). Non-parametric and parametric tests of pairwise correlation show that investment is indeed significantly higher for players with a higher in-degree. ${ }^{17}$

- Insert Figure 3 here -

To get more insight into investment sharing we next analyze the network structure. A direct examination of linking patterns reveals that the network is connected in over $90 \%$ of the cases, see Table 4 . Table 2 shows that there is significant linking activity (in all treatments). ${ }^{18}$

\section{- Insert Table 4 here -}

Taken together, these observations offer strong support for investment sharing in the laboratory. Finally, from Table 3 we note that aggregate earnings of subjects are typically lower than the lowest equilibrium payoffs (in the homogeneous treatment with $k=36$, as well as in all heterogeneous treatments).An analysis of best response behavior reveals that overall, given the linking decisions, players could on average have earned 6 points more by

\footnotetext{
${ }^{17}$ The Pearson correlation coefficient between in-degree and investment is 0.42 for the homogeneous Treatments I-III, and 0.44 for the heterogeneous Treatments IV-VI (both at the $1 \%$ level of statistical significance). The positive correlation between in-degree and investment is also confirmed in an OLS regression, with investment as the dependent variable, and in-degree and all levels of linking costs $k$ as independent variables. This is reported in Table B.2, in Appendix B, where Model 1 in the first column presents the data from the baseline Treatment I $(k=10, c=5)$.

${ }^{18}$ Although equilibrium outcomes arise very rarely in the laboratory, $25.4 \%$ of all groups are in a network structure as described by equilibrium (for evidence on this refer to Table B.3 in Appendix B).
} 
optimally adjusting their investment to their neighbors' investment, and on average 3.9-13.2 points additionally by adjusting links optimally. However, we do observe a significant fall in aggregate earnings as we raise the costs of linking from $k=10$ to $k=36$. Earning were thus only about $9 \%$ below the theoretically predicted value.

\subsection{Hypotheses testing}

We now turn to the central question regarding the impact of changing linking costs. Hypothesis 1 predicts (for the homogeneous treatments) that an increase in linking costs (a) reduces the number of hubs, (b) raises investments by hubs, and (c) reduces the number of links, while (d) individually accessed as well as aggregate investment remains unchanged, and (e) aggregate earnings fall.

The theory defines a hub as a player who invests $x_{i}>k / c$, such that other players find it worthwhile to link to this player. For $k=10,24,36$ and $c=5$, these critical investment levels are $2,4.8$, and 7.2, respectively. Note that, to test whether the investment by hubs increases with rising linking costs, we should not use a definition that is based on rising investment thresholds, as this would bias our estimates. We therefore use a definition that is based on a player's incoming links (in-degree). We define someone as 'Hub2' if she has an in-degree larger than or equal to 2, and someone as 'Hub3' if she has an in-degree larger than or equal to 3 . While the first definition is in line with the equilibrium predictions for the treatments $k=\{10,24\}$, it is too lenient 
for $k=36$. The second definition is in line with the theoretical predictions for treatment $k=36$. It also allows for a conservative test of our theory when applied to the other two treatments.

In Table 5, the columns 'Hub2' and 'Hub3' show the number of players qualifying as a hub, as well as the average number of hubs per group. Overall, we find clear evidence for a decline in the number of hubs when linking costs increase from $k=10$ to $k=24$ or $k=36$ (Hub2) and from $k=10$ or $k=24$ to $k=36$ (Hub3), largely supporting Hypothesis 1 (a). ${ }^{19}$

Table 5 shows investment subjects that qualify as a Hub2 or as a Hub3: for both hub definitions investment levels for $k=24$ and for $k=36$ are significantly higher than for $k=10$ (statistically significant at the $1 \%$ level), while the investment levels for $k=24$ and $k=36$ do not differ statistically. ${ }^{20}$ Thus, we interpret this as support for Hypothesis 1(b). ${ }^{21}$

\footnotetext{
${ }^{19}$ Kolmogorov-Smirnov tests comparing the number of hubs in one treatment with the remaining two levels of $k$, show that there are significantly more subjects with an in-degree of at least 2 (Hub2) when $k=10$ compared with $k=24$ or $k=36$ (statistically significant at the $1 \%$ level). There is, however, no significant difference between the treatments with $k=24$ and $k=36$. At the same time we find that significantly fewer subjects had an indegree of 3 (Hub3) when $k=36$ compared with $k=24$ or $k=10$ (statistically significant at the $1 \%$ level). We do not find a significant difference between the treatments with $k=10$ and $k=24$.

${ }^{20}$ Table B.2 in Appendix B shows a positive correlation between in-degree and investment in general. Model 2 shows the estimations for the data from the heterogeneous Treatment IV with $k=10$, Model 3 for all data from the homogeneous Treatments I-III pooled, Model 4 for all data from the heterogeneous Treatments IV-VI, and Model 5 for all data of the full sample (Treatments I-VI) pooled. In Models 3 to 5, dummies for the treatments with linking costs $k=10$ and $k=36$ are added. The results show that with lower linking costs, $k=10$, individual investment is lower. The dummy for $k=36$ in Model 3 is close to statistical significance with a $t$-value ( $p$-value) of $1.565(0.118)$ when compared to $k=24$.

${ }^{21}$ Note that theory does not predict a specific slope for the increase of investments by hubs. According to Table 5 such a slope is likely to be concave: we find a significant
} 
— Insert Table 5 here -

We next turn to the number of links. Table 3 on group descriptives reports the mean (and median) number of directed ties per group. We see that there are 5, 4 and 3 links as we vary costs of linking from $k=10$ to $k=36$. Confirming Hypothesis $1(\mathrm{c})$, we find that higher levels of linking costs are associated with lower levels of linking. ${ }^{22}$

We next consider aggregate investment. Table 3 reveals that it is growing with cost of linking: in the homogeneous treatments, it is, on average, 15.18 at $k=10$, rises to 17.59 at $k=24$ and then rises further to 19.47 at $k=36$. This rise of aggregate investment is statistically significant at the $5 \%$ level (for $t$-tests, the Wilcoxon rank-sum tests as well as a Kolmogorov-Smirnov tests across levels of $k$ ). With the same tests we also confirm statistically that aggregate investment is higher than 12 (at the $1 \%$ level of significance). This is a clear departure from the theoretical prediction in Hypothesis 1(d). However, note that, as theoretically predicted (see Proposition 1 and Figure 1), the mean and median individually accessed investment does not change in the level of linking costs $k .^{23}$ We provide an explanation for the deviation concerning aggregate investment in Section 3.3 below.

increase in hub investments as costs of linking move from $k=10$ to $k=24$, which then levels out between $k=24$ and $k=36$.

${ }^{22} \mathrm{~A}$ Wilcoxon rank-sum test (and also the Kolmogorov-Smirnov test) shows that the respective differences are statistically significant at the $1 \%$ level for $k=24(k=36)$ and $k=10$, and at the $5 \%$ level for $k=24$ and $k=36$.

${ }^{23} T$-tests show $p$-values of 0.187 and 0.631 across levels of $k=10$ and $k=24$, and of $k=24$ and $k=36$, respectively. The corresponding $z$-values of Wilcoxon rank-sum tests are $z=0.328$ and $z=0.861$, respectively. 
Finally, we consider aggregate earnings. Recall that at $k=10$ and at $k=24$ there are multiple equilibria (with possibly 1-4 hubs and 1-2 hubs, respectively), while at $k=36$ there exists a unique equilibrium (with a single hub). As aggregate investment is constant at 12 in all cases aggregate earnings are falling in the number of links in an equilibrium: the equilibrium with a single hub is efficient. If we focus on the efficient equilibrium then it is easy to check that aggregate earnings will fall by 78 as the costs of linking increase from $k=10$ all the way to $k=36$. This is the maximum decline in equilibrium earnings possible as we raise costs of linking. On the other hand, the minimum fall in earnings is 48 and corresponds to the case when players choose the 4 -Star equilibrium when $k=10$. Table 3 reports the movement in aggregate earnings across different linking cost treatments. We find a significant drop in median earnings - from 680 to 611 - as we raise costs from $k=10$ to $k=36 .{ }^{24}$ Thus the experiment supports Hypothesis 1(e), aggregate welfare are falling sharply in costs of linking.

We next turn to effects of heterogeneity in the costs of investment. Hypothesis 2 predicts that, if linking costs are low $(k=10)$, heterogeneity with respect to costs of investment increases specialization: (a) the low-cost player is the hub. Moreover, heterogeneity (b) reduces the number of hubs, (c) raises investment by hubs, and (d) lowers the number of links when compared to the homogeneous case, while (e) aggregate investment rises.

\footnotetext{
${ }^{24}$ This fall of aggregate earnings is statistically significant at the $1 \%$ level across all levels of $k$ (Wilcoxon rank-sum test as well as a Kolmogorov-Smirnov test).
} 
First we test whether the low-cost player is a hub player. Here we follow the theoretical prediction for the heterogeneous treatments and focus on Hub3 (someone who has an in-degree equal to 3), because the definition of Hub2 would be too lenient and bias our results in favour of the theory. Table 6 presents logistic estimations for Treatment IV and for all heterogeneous Treatments IV-VI with a dummy for Hub3 as the dependent variable (Columns 1 and 3). As our most important variable of interest we include a dummy for the low-cost player as explanatory variable. ${ }^{25}$ For robustness, Table 6 also reports all estimations for Hub2 (Columns 2 and 4). The results of all econometric specifications clearly confirm Hypothesis 2(a): for a low-cost player the odds of being a Hub3 (or Hub2) are 5.69 (or 4.15) times larger than for high-cost players.

- Insert Table 6 here -

We further examine the effect of cost heterogeneity on the number of hubs. Table 5 shows that the average number of players per group that qualify as a Hub3 in the heterogeneous Treatment IV is 0.69 , but not significantly lower than the corresponding average in the homogeneous baseline treatment (0.68). This also applies to Hub3-comparisons between heterogeneous and homogeneous treatments for $k=24$ (0.62 vs 0.61). ${ }^{26}$ Thus, Hypothesis 2(b)

\footnotetext{
${ }^{25}$ All control variables of the econometric specification in Table B.2 are also included in Table 6, with the exception of a dummy for $c$, as we focus on the heterogeneous sample only. We added dummies for sessions and periods to control for unobserved heterogeneity between sessions and periods, e.g., due to experience or learning of subjects during the sessions.

${ }^{26}$ For $k=36$ theory predicts that there should not be a difference, and this is indeed
} 
is not confirmed.

Despite the fact that investment by Hub3 players is lower than the theoretically predicted level of 13 , it is higher in the heterogeneous treatment than in the homogeneous treatment. ${ }^{27}$ Moreover, the subgroup of Hub3 players that are also low-cost players in Treatments IV, V and VI invest significantly more than the Hub3 players in Treatments I, II and II respectively. ${ }^{28}$ Hence, overall, we find some support for Hypothesis 2(c).

Table 3 shows that networks in the heterogeneous Treatment IV with $k=10$ have, on average, 4.97 directed links, which is more than theoretically predicted (3 links, for all heterogeneous treatments) and statistically not different from the average number of links in the corresponding homogenous Treatment I (4.84). Hence, we find no support for Hypothesis 2(d), which predicted a lower number of links in the homogeneous treatment.

Table 3 also reports equal aggregate investments in Treatment IV and Treatment $\mathrm{I}^{29}$ In addition, the OLS analysis presented in the last column of Table B.2 in Appendix B (Model 5) reveals that individual investment confirmed (0.47 vs 0.41$)$.

${ }^{27} \mathrm{~A} t$-test comparing the mean investments of Hub3 players in the heterogeneous with the homogeneous treatment (see Table 5) is not significant. However, a one-tailed test shows a marginally significant effect with $p=0.077$. As our hypothesis predicts a clear direction, we interpret this as indicative support.

${ }^{28} \mathrm{~A}$ Wilcoxon rank-sum and a t-test (unreported) show that the investment levels of the subgroup of Hub3 players that are also low-cost players in Treatment IV are higher (statistically significant at the 1\% level) than the investment levels of Hub3 players in the baseline Treatment I. This also applies to respective comparisons of Hub3 investment levels between Treatments II and V (at the 5\% level), and between Treatments III and VI (at the $1 \%$ level).

${ }^{29}$ Neither the medians (both 14 units) nor the means (15.39 for Treatment IV; 15.18 for Treatment I) are statistically different (Wilcoxon rank-sum and $t$-test). 
is not significantly higher for heterogeneous treatments: the coefficient of a dummy for the homogeneous treatments is not significantly different from zero. This also applies when we rerun Model 5 of Table B.2 with Treatments I and IV only (unreported). Overall, we do not find any difference between heterogeneous and homogeneous low-cost treatments, and therefore also no support for Hypothesis 2(e).

Finally, we note that the theory predicts that with heterogeneous costs, the aggregate investment must remain constant with respect to costs of linking. An inspection of Table 3 reveals that aggregate investments are rising in costs of linking, from 14 all the way to 19, as we increase the costs of

linking from $k=10$ to $k=36$. Thus the experiment with heterogeneous costs clearly violates this prediction of the theory. While the theoretical predictions are clear-cut for the heterogeneous treatments, our results indicate that subjects did not perceive these treatments to be qualitatively different from the homogeneous treatments.

Our experiments, both with the homogenous and the heterogeneous costs, present one consistent violation of the theoretical prediction: aggregate investments are rising in the costs of linking. The next section develops an explanation for this violation.

\subsection{Findings on aggregate investment}

The results in the previous section revealed that, while the median subject accesses the theoretically predicted investment (see Section 3.1), the aggre- 
gate investment level is higher than $\hat{y}=12$ and is increasing with linking costs. This violates an important prediction of the theory (Hypothesis 1d).

We now propose a simple model to help us understand the patterns in aggregate investment. We start by noting that in the original model of Galeotti and Goyal (2010), players make their choices simultaneously. By contrast, in the experiment, players make choices sequentially and repeatedly, and there is an uncertain end point. Given these significant departures from the model, we interpret the consistency between the theoretical predictions and the data as strong support for key trade-offs faced by individuals in private investments and linking. There is, however, one important dimension - aggregate investment - on which there is clear difference between the theoretical prediction and the experimental data. In what follows, we propose a simple notion of stability to explore the role of strategic posturing in a dynamic setting.

The model we develop is an attempt at bridging the gap between the static theoretical model and the possibilities of strategic posturing created by the dynamic game being played in the experiment. Our model builds on earlier work by Bramoullé and Kranton (2007) on the stability of investment behaviour on fixed networks, and Page and Wooders (2009) and Dutta et al. (2009) on the stability of network formation processes.

The main idea here is that, toward the end of the game, players explore small and local moves to improve their payoffs. In this exploration they take into account the possible response of other players but as time is short they 
do not believe that it is worth working through the consequences of long sequences of moves and counter moves. More formally, given a profile $s$, a player $i$ asks if she can change her investment or her linking and if that can conceivably improve her payoffs, given that possibly one other player may have a chance to respond. A strategy profile $s$ is said to be stable if there exists no small and local deviation that may be profitable in this sense.

We start with an analysis of the stability of the equilibrium predictions in the theoretical model. The first observation is that a hub player has an incentive to shade their investments: if the shading is very large peripheral player(s) will best respond by deleting links but if the shading is small then they will best respond by simply raising their investment correspondingly. In this situation, the payoffs of the hub player will definitely increase. We have thus shown that the equilibrium outcomes identified in Treatments I-III are not stable in a dynamic setting

We now turn to the study of stable outcomes. Following on the above argument, the next step is to develop bounds on the level of shading that the hub-player can practice. Our analysis of these bounds is summarized as follows:

OBSERVATION: Fix a strategy profile $s$ in which the network is a coreperiphery network with $m$ hub players and $n$-m periphery players. Let $x_{i}$ denote investment by a hub-player and $x_{j}$ the investment by a periphery player. 
This profile is stable only if the investments respect the following restrictions:

$$
x_{i}=\frac{k}{c}+\frac{z^{*}}{m} ; \quad x_{j}=\hat{y}-\frac{m k}{c}-z^{*}
$$

with

$$
\hat{y}-\frac{(m+1) k}{c}<z^{*}<\hat{y}-\frac{m k}{c} .
$$

We note an important feature of these investment restrictions: a hub player accesses investments in excess of $\hat{y}$, while periphery players access investments exactly equal to $\hat{y}$.

The key step is the derivation of the bounds on $z$ and we present it here; the rest of the derivation is presented in Appendix A. Consider the incentives to reduce investments by the periphery: in the dynamic setting there is the possibility that the hub player responds by raising her investment. We now show that if $z$ is small then the hub is accessing sufficient investments and will not raise his investment in response. To check this let us take the investment of this one periphery player all the way down to 0 . The hub will still access

$$
m\left(\frac{k}{c}+\frac{z}{m}\right)+(n-m-1)\left(\hat{y}-\frac{m k}{c}-z\right)
$$

And it may be checked that this is in excess of $\hat{y}$ if

$$
z<\hat{y}-\frac{m k}{c}
$$


(for $n-m \geq 2$ ).

As periphery players get no incoming links, their investments must be justified (in themselves), and there must be no incentive to form a link with another peripheral player. As aggregate investments accessed by a peripheral player are $\hat{y}$, we only need to check the no-new-link constraint, i.e., $x_{j}<k / c$. This is true if

$$
z>\hat{y}-\frac{(m+1) k}{c}
$$

Putting together these two conditions gives us the required restrictions on $z^{*}$. We now illustrate the implication of these restrictions, for our different cost treatments. To fix ideas we focus on the case of a single hub.

Consider the low cost case $k=10$ : we can compute the bounds for $z$ to be $8<z<10$. The hub player sets minimum possible investment and so we get $x_{i}=10$ and $x_{j}=2$. So aggregate investment is equal to 16 . In the medium costs case, $k=24$, the bounds for $z$ are $2.4<z<7.2$. The hub player sets $x_{i}=7.2$ and $x_{j}=4.8$. So aggregate investment is equal to 21.6. Finally, consider the high cost case, $k=36$. It is easy to compute that $-2.4<z<4$.8. The hub player sets minimum possible $z$, i.e., $z=0$. We then get $x_{i}=7.2$ and $x_{j}=4.8$. So aggregate investment is equal to 21.6. We can use similar methods to compute the bounds on $z$ for outcomes with multiple hub players. They are presented in the appendix and indicate that aggregate investment will be lower in case there are multiple hubs. 
Taken together, our computations demonstrate one, that aggregate investments in a stable outcome in the dynamic model can be larger than the equilibrium investments in the original static model and two, that they are increasing in linking costs. These two predictions are consistent with the patterns observed in our experiment.

To close the circle, we now return to the data from our experiments and show that an important prediction of this new model is also satisfied: hubs typically over-invest relative to the static best response, while periphery players roughly play a best response in investment levels.

Table 4 shows that in the baseline treatment the network is connected in over $92 \%$ of the cases. Table 7 shows that in Treatments I and II the hub does indeed over-invest relative to the best response given his neighbours' choices, while the non-hubs choose actions roughly in line with their best response. ${ }^{30}$

— Table 7 here -

We conclude by showing that the investment shading practiced by the hubs has large payoff effects. Table 8 presents data on payoffs of hubs and peripheral players and shows that hub players on average over all treatments earn 5.5 points more than the highest static equilibrium profit while the non-hubs earn 25.34 points less than the lowest static equilibrium profit. An

\footnotetext{
${ }^{30}$ It seems that in the heterogeneous treatments the high-cost players were less willing to adjust their investments upwards to the shading by the (low-cost) hubs (Table 7 shows that they on average invest less than the best response level), possibly because the role of a hub was exogenously given.
} 
analysis of best response behavior reveals that overall, players could have earned 6 points more by optimally adjusting their investment to their neighbors' investment.

This adjustment neglects the dynamic process characterized above. Comparing realized profits to the profits of the stable outcome of the above characterized dynamic game reveals that in the homogeneous treatments hubs could have earned on average $7.25(\simeq 4 \%)$ points more, while non-hubs could have earned $16.4(\simeq 10 \%)$ points more. In the heterogeneous treatments hubs could have earned 17.94 points $(\simeq 8 \%)$ more, while non-hubs earned on average $1.51(\simeq 1 \%)$ points more than in the stable outcome. In general hubs earn significantly more than peripheral players (statistically significant at the $1 \%$ level); this order of earnings reverses the ranking of equilibrium payoffs in the static Galeotti-Goyal model!

— Table 8 here -

\section{Conclusion}

Individuals and organizations acquire information privately and also invest in links with others to access information indirectly. This paper presents an experiment on the economic consequences of changes in the relative cost of these two activities. The experiment is based on a theoretical model of local public goods and linking. 
We find that a decline in linking costs has large effects: individual investments are more dispersed and they are accompanied by greater linking activity and hence, denser social networks. Aggregate investment falls, but investment accessed by individuals remains stable, due to increased networking. The overall effect is an increase in individual utility and aggregate welfare.

Our experiment is conducted with groups of 4 subjects. In future work, it would be important to test the scope of the theory by conducting experiments on significantly larger groups.

Affiliations:

Stephanie Rosenkranz: Department of Economics, Utrecht University. Email: s.rosenkranz@uu.nl

Utz Weitzel: Department of Economics, Utrecht University, and Department of Economics, Radboud University Nijmegen. Email: u.weitzel@uu.nl

Vincent Buskens: Department of Sociology, Utrecht University. Email: vbuskens@uu.nl 


\section{References}

[1] Aral, S. and D. Walker (2012). 'Identifying influential and susceptible members of social networks', Science, 337-341

[2] Bala, V. and Goyal, S., (2000). 'A noncooperative model of network formation', Econometrica 68(5), pp. 1181-1229.

[3] Benoît, J., and Krishna, V. (1985). 'Finitely repeated games', Econometrica, 43(4), pp. 905-922.

[4] Bramoullé, Y., and R. Kranton (2007). 'Public goods in networks', Journal of Economic Theory, 135(1), pp. 478-494.

[5] Burger, M., and V. Buskens (2009). 'Sncial context and network formation: an experimental study', Social Networks 31(1), pp. 63-75.

[6] Cassar, A., (2007). 'Coordination and cooperation in local, random and small world networks: experimental evidence', Games and Economic Behavior 58(2), pp. 209-230.

[7] Callander, S. and Plott, C., (2005). 'Principles of network development and evolution: an experimental study', Journal of Public Economics 89(8), pp. 1469-1495.

[8] Charness, G. and Corominas-Bosch, M., Frechette, G. R., (2007). 'Bargaining and network structure: an experiment', Journal of Economic Theory 136(1), pp. 28-65. 
[9] Charness, G., F. Feri, M. Meléndez-Jiménez and M. Sutter, (2014) 'Experimental games on networks: underpinnings of behavior and equilibrium selection', Econometrica, 82(5), pp. 1615-1670

[10] Croson, R (2010). 'Public goods experiments', in (S. Durlauf and L. Blume, eds.) Palgrave Dictionary of Economics.

[11] Dolder, D. van, and V. Buskens (2014). 'Individual choices in dynamic networks: an experiment on social preferences', PloS ONE 9(4): e92276

[12] Dutta, B., Ghosal, S., \& Ray, D. (2005). 'Farsighted network formation', Journal of Economic Theory, 122(2), pp. 143-164.

[13] Falk, A., and Kosfeld, M., (2012). 'It's all about connections: evidence on network formation', Review of Network Economics 11(3), Article 2.

[14] Farrell, J., and M. Rabin (1996). 'Cheap talk', Journal of Economic Perspectives, 10(3), pp. 103-118.

[15] Fischbacher, U., (2007). 'Z-Tree. Zuerich toolbox for ready-made economic experiments', Experimental Economics 10(2), pp. 171-178.

[16] Frankort, H. T. W., J. Hagedoorn, and W. Letterie (2012). 'R\&D partnership portfolios and the inflow of technological knowledge', Industrial and Corporate Change 21(2), pp. 507-37.

[17] Galeotti, A., and S. Goyal, (2010). 'The law of the few', American Economic Review 100, pp. 1468-1492. 
[18] Goeree, J. K., Riedl, A. and A. Ule, (2009). 'In search of stars: network formation among heterogeneous agents', Games and Economic Behavior 67(2), pp. 445-466.

[19] Goyal, S., (1993). 'Sustainable communication networks', Tinbergen Institute Discussion Paper, TI 93-250.

[20] Goyal, S., (2007), Connections: An Introduction to the Economics of Networks. Princeton University Press.

[21] Holt, C., and S. Laury (2012). 'Voluntary provision of public goods: experimental results with interior Nash equilibria', forthcoming in the Handbook of Experimental Economic Results, (eds) C. Plott and V. Smith. New York: Elsevier Press.

[22] Kosfeld, M., (2004). 'Economic networks in the laboratory: a survey', Review of Network Economics 3(1), pp. 20-42.

[23] Ledyard, J (1995). 'Public goods: a survey of experimental research', in (J. Kagel and A. Roth, eds.) Handbook of Experimental Economics.

[24] Leeuwen, B. van, T. Offerman and A. Schram (2013). 'Superstars need social benefits: an experiment on network formation', Tinbergen Institute Discussion Paper 2013-112/I.

[25] Page, F. H., and Wooders, M. (2009). 'Strategic basins of attraction, the path dominance core, and network formation games', Games and Economic Behavior, 66(1), pp. 462-487. 
[26] Peitz, M., and J. Waldfogel (2012). The Oxford Handbook of the Digital Economy, Oxford University Press.

[27] Rong, R. and D. Houser (2012). 'Emergent star networks with ex ante homogeneous agents', George Mason University Interdisciplinary Center for Economic Science Paper No. 12-33.

[28] Rosenkranz, S. and U. Weitzel, (2012). 'Network structure and strategic investments: an experimental analysis', Games and Economic Behavior 75(2), pp. 898-920.

[29] Varian, H. (2010). 'Computer mediated transactions', American Economic Review: Papers and Proceedings, 100(2), pp. 1-10. 


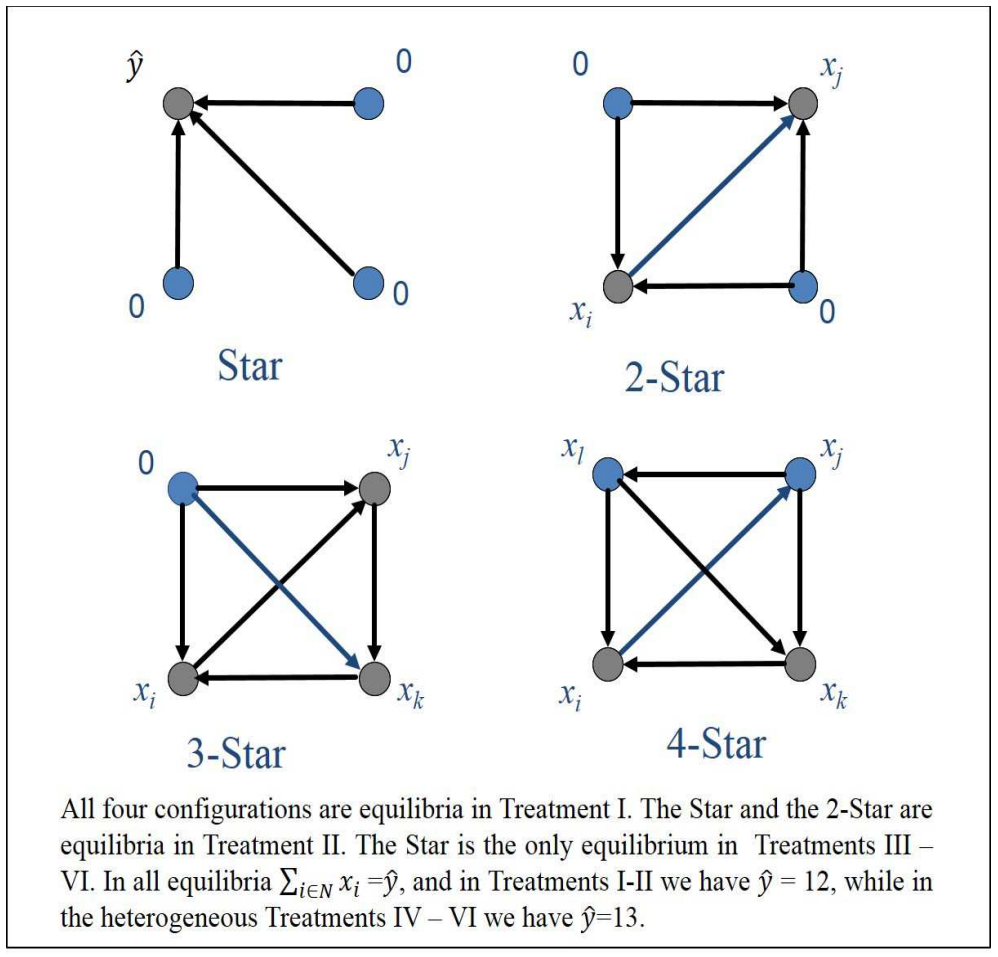

Figure 1: Equilibrium Configurations in Treatments I to VI.

\begin{tabular}{cccc} 
& \multicolumn{3}{c}{ Costs of information acquisition } \\
& $k=10$ & $k=24$ & $k=36$ \\
\hline Homogeneous, $c=5$ & I & II & III \\
\hline Heterogeneous, $c_{i}=3$ & IV & V & VI
\end{tabular}

Table 1: Treatments in the Experiment 


\begin{tabular}{lccccc} 
& $N^{*}$ & Mean & SD & Min & Max \\
\hline Age & 152 & 21.37 & 2.454 & 17 & 31 \\
\hline Friends in the lab & 152 & 0.71 & 1.183 & 0 & 6 \\
\hline Male & 152 & $35.5 \%$ & 0.48 & 0 & 1 \\
\hline Foreign nationality & 152 & $38.2 \%$ & 0.487 & 0 & 1 \\
\hline Investment (final decision) & 2736 & 4.4 & 3.364 & 0 & 30 \\
\hline In-degree (final decision) & 2736 & 1.03 & 1.09 & 0 & 3 \\
\hline Out-degree (final decision) & 2736 & 1.03 & 0.841 & 0 & 3 \\
\hline Linking decisions (per node, round) & 38485 & 24.75 & 16.387 & 1 & 91 \\
\hline Investment decisions (per node, round) & 96166 & 52.02 & 32.434 & 1 & 241 \\
\hline (N-152 subjects multiplied by 18 non-trial rounds) & & & &
\end{tabular}

( $N=152$ subjects multiplied by 18 non-trial rounds).

Table 2: Descriptive Statistics of Sample

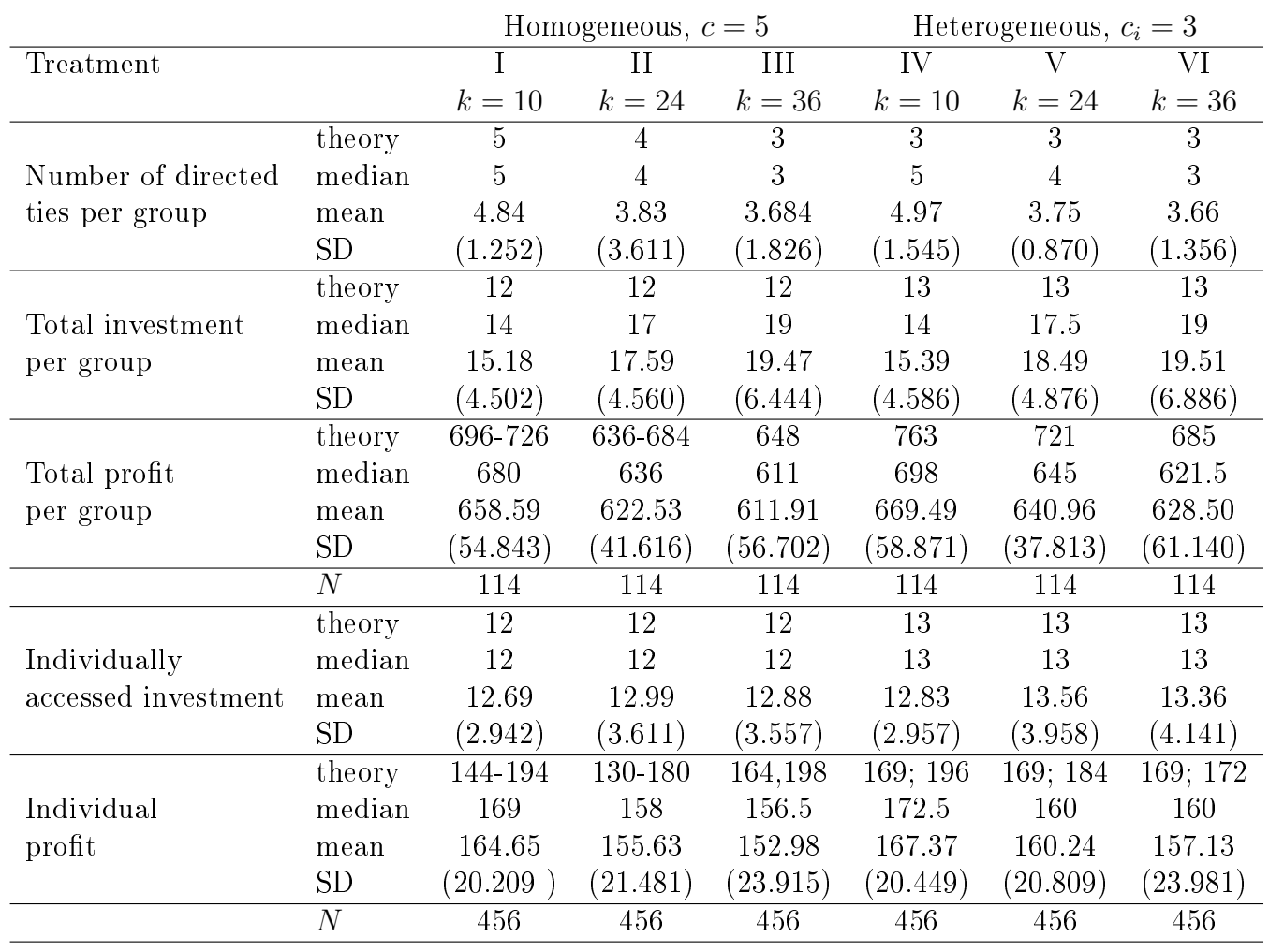

Table 3: Descriptive Statistics at the Group Level 

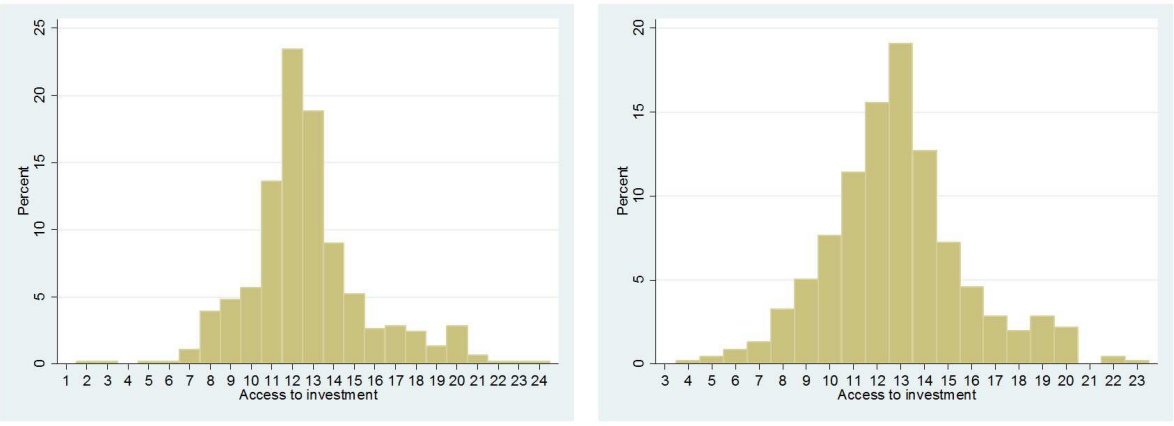

Figure 2: Distribution of Investment Available to Individuals in Treatment I $(c=5, k=10)$ and Treatment $I V(c=3, k=10)$

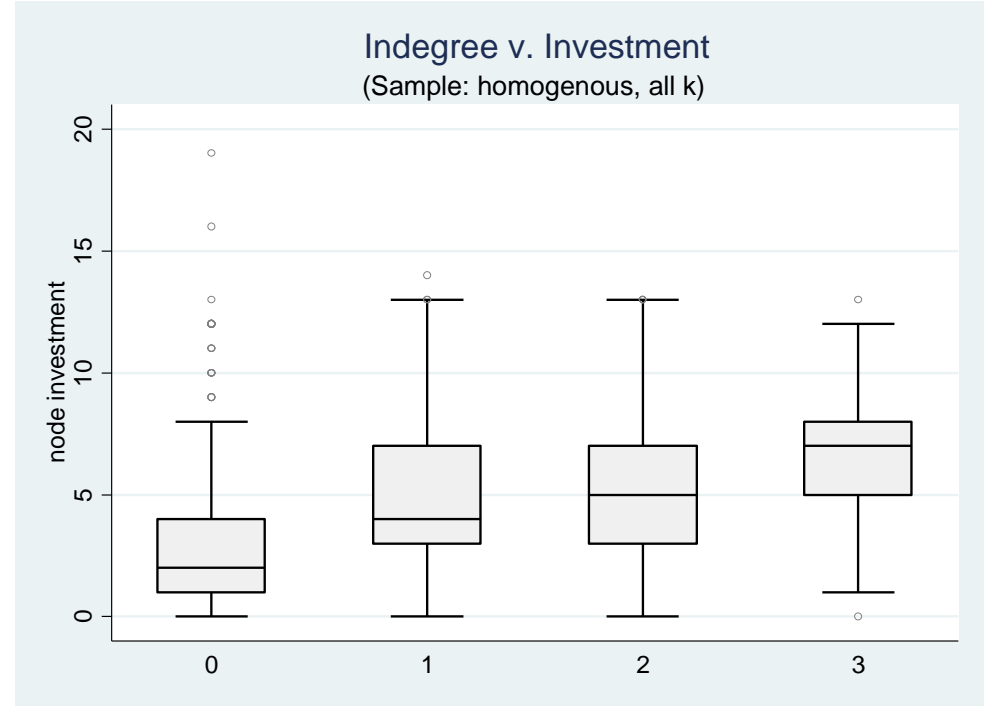

Figure 3: Box Plot Investment Versus In-degree 


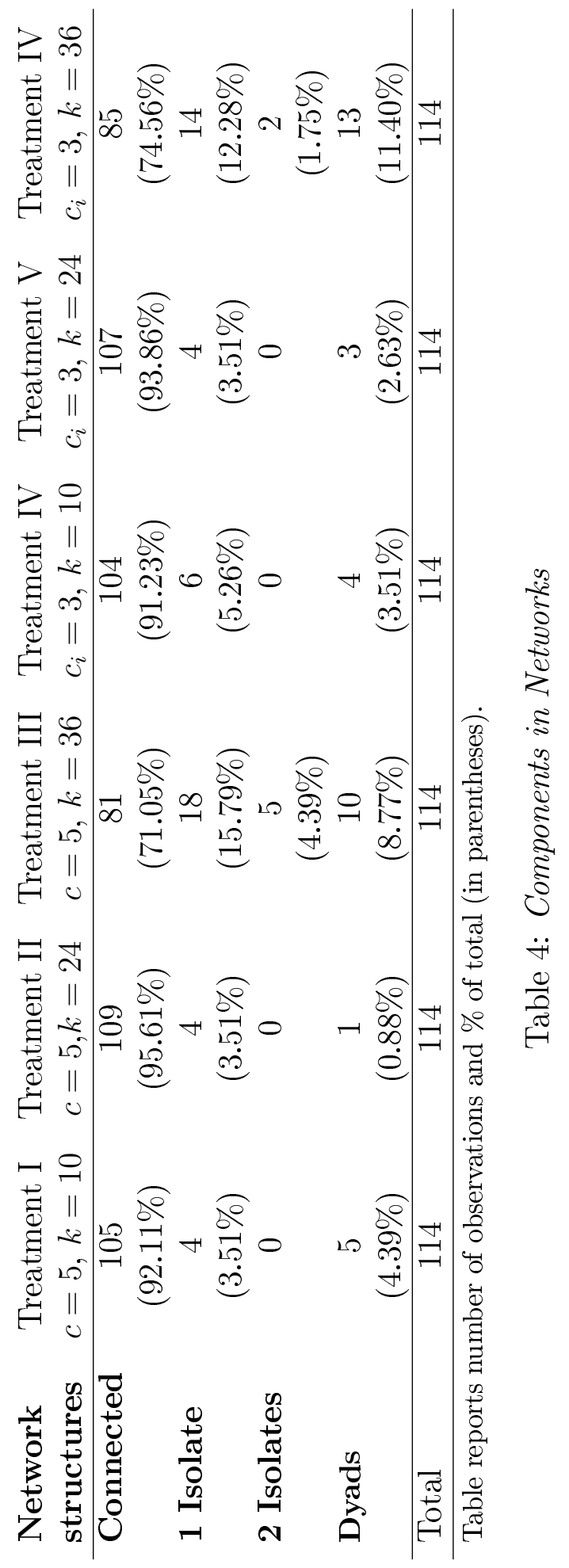




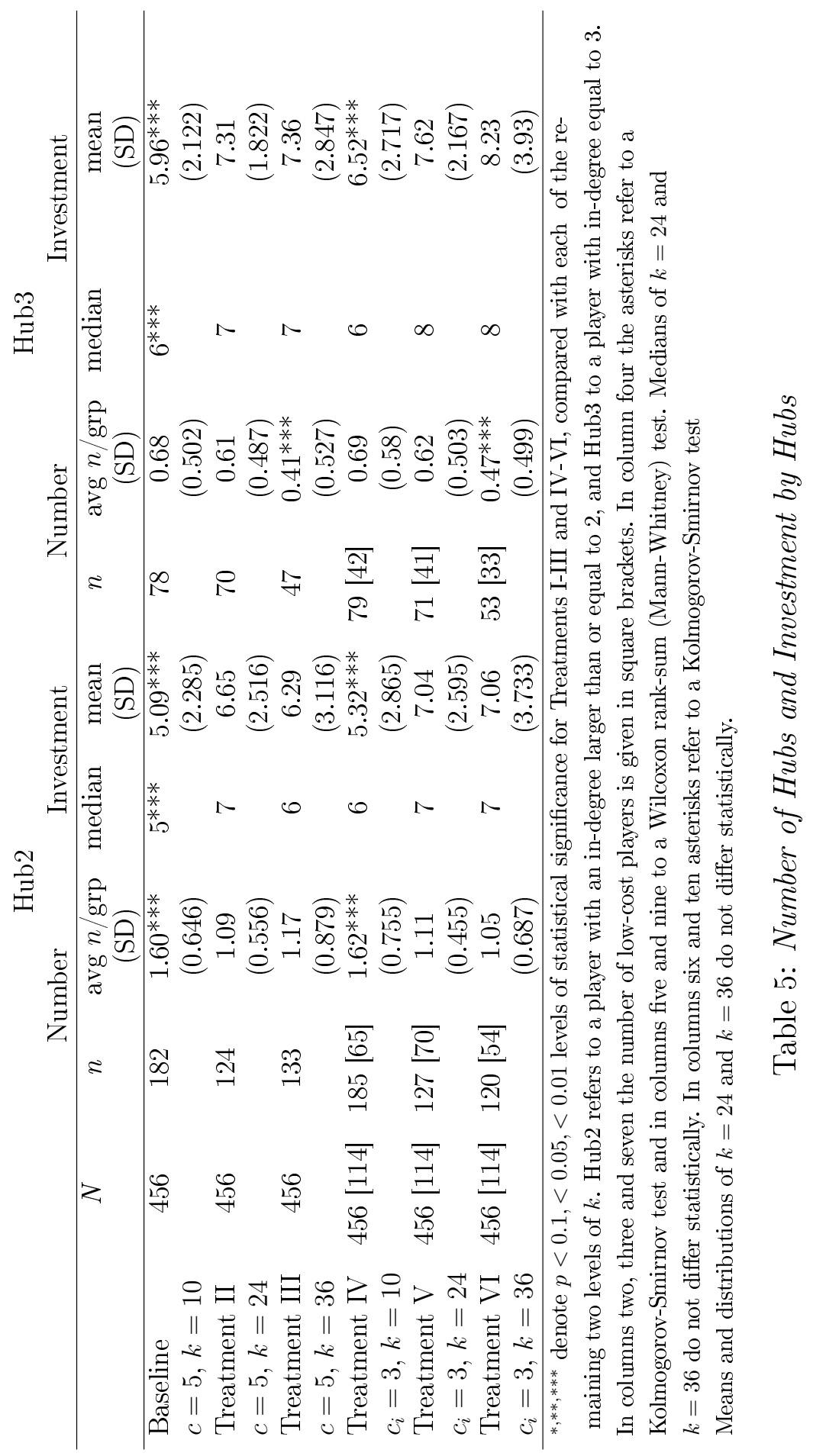




\begin{tabular}{lcccc}
\hline & Hub3 & Hub2 & Hub3 & Hub2 \\
& Treatment IV & Treatment IV & Treatments IV-VI & Treatment IV-VI \\
\hline low-cost player & $5.065^{* * *}$ & $2.648^{* * *}$ & $5.692^{* * *}$ & $4.152^{* * *}$ \\
& {$[5.349]$} & {$[3.420]$} & {$[9.529]$} & {$[8.968]$} \\
$k=10$ & & & 1.032 & $2.146^{* * *}$ \\
& & & {$[0.101]$} & {$[2.847]$} \\
$k=36$ & & 0.613 & 1.062 \\
& & & {$[-1.480]$} & {$[0.208]$} \\
Session dummies & yes & yes & yes & yes \\
Period dummies & yes & yes & yes & yes \\
No. observations & 456 & 456 & 1368 & 1368 \\
No. clusters & 114 & 114 & 342 & 342 \\
Log Likelihood & -186.224 & -282.441 & -508.682 & -779.102 \\
Pseudo $R^{2}$ & 0.114 & 0.083 & 0.114 & 0.087 \\
$\chi^{2}$ & 49.899 & 167.07 & 112.034 & 160.553 \\
Prob $>\chi^{2}$ & 0.000 & 0.000 & 0.000 & 0.000 \\
\hline Table reposts & & & & \\
\hline
\end{tabular}

Table reports odds ratios; z-values in square brackets; standard errors clustered at the group level.

${ }^{*} p<0.1,{ }^{* *} p<0.05,{ }^{* * *} p<0.01$. Hub2 refers to a player with an in-degree larger than or equal to 2 , and Hub3 to a player with in-degree equal to 3.

Table 6: Logistic Estimation on the Likelihood of Being a Hub in the Heterogeneous Treatments 


\begin{tabular}{llcccccc} 
& & \multicolumn{3}{c}{ Homogeneous, $c=5$} & \multicolumn{3}{c}{ Heterogeneous, $c_{i}=3$} \\
Hub2 & & I & II & III & IV & V & VI \\
& & $k=10$ & $k=24$ & $k=36$ & $k=10$ & $k=24$ & $k=36$ \\
\hline Hubs: & investment & 5.09 & 6.65 & 6.29 & 5.32 & 7.04 & 7.06 \\
& best-response & 3.98 & 4.25 & 4.36 & 4.99 & 4.81 & 5.73 \\
& $z$-value & 0.000 & 0.000 & 0.000 & 0.292 & 0.000 & 0.000 \\
\hline Non-hubs: & investment & 2.93 & 3.56 & 4.28 & 2.84 & 3.69 & 4.10 \\
& best-response & 2.97 & 3.73 & 4.33 & 3.71 & 4.30 & 4.80 \\
& $z$-value & 0.604 & 0.595 & 0.918 & 0.000 & 0.000 & 0.000 \\
\hline \hline Hub3 & & I & II & III & IV & V & VI \\
& & $k=10$ & $k=24$ & $k=36$ & $k=10$ & $k=24$ & $k=36$ \\
\hline Hubs: & investment & 5.93 & 7.31 & 7.36 & 6.52 & 7.62 & 8.23 \\
& best-response & 4.41 & 3.74 & 4.77 & 5.86 & 4.14 & 6.32 \\
& $z$-value & 0.000 & 0.000 & 0.000 & 0.128 & 0.000 & 0.000 \\
\hline Non-hubs: & investment & 3.35 & 3.87 & 4.58 & 3.29 & 4.07 & 4.44 \\
& best-response & 3.16 & 3.90 & 4.29 & 3.89 & 4.49 & 4.88 \\
& $z$-value & 0.170 & 0.718 & 0.023 & 0.000 & 0.000 & 0.000 \\
\hline
\end{tabular}

The z-values correspond to Wilcoxon rank-sum tests, significance is also confirmed in $t$-tests. Hub2 refers to a player with an in-degree larger than or equal to 2, and Hub3 to a player with in-degree larger than or equal to 3 .

Table 7: Best-response for Hubs and Non-hubs 


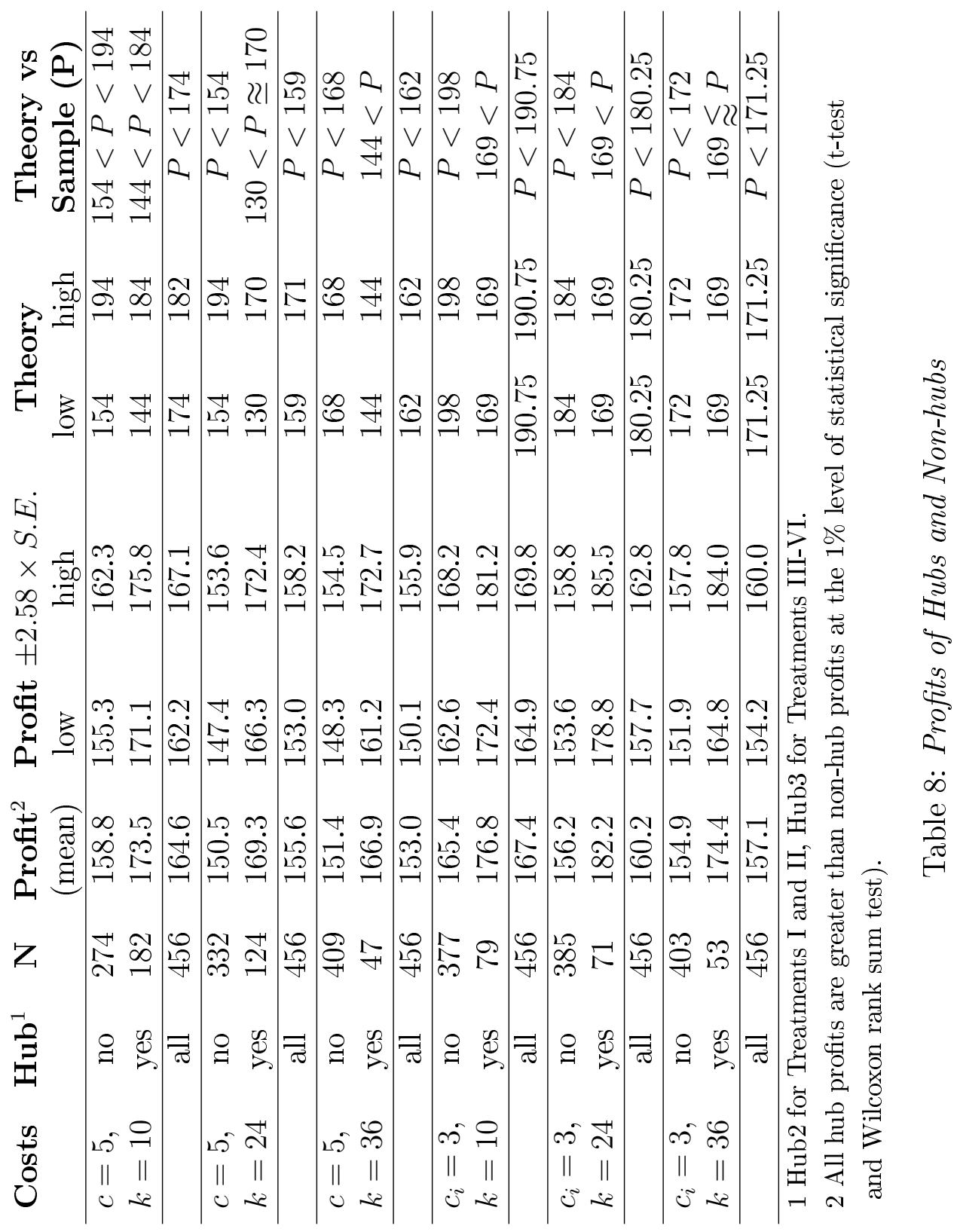




\section{Appendix A}

1. In Treatments I-III, aggregate investments in equilibrium are equal to 12.

Proof: The proof exploits the assumption that investments take integer values and that $n=4$. First, we prove that in equilibrium the network is connected. Suppose it is not connected then we need to consider networks of one, two, three (and four) isolated players and networks with disconnected pairs. Observe that no network with a single isolated player is an equilibrium: this is because the isolated player will optimally choose 12 . But then from Galeotti and Goyal (2010) we know that there must be only one hub, which contradicts the hypothesis that the player is isolated. So we need to consider the case of two disconnected pairs only. When $k=10$ or 24 , in each pair there is at least one player who chooses 6 or more. But then the larger investing player in one pair has an incentive to form a link with the larger investing players in the other pair. When $k=36$, it follows that in each pair the higher investing player is choosing 8 or more. But then the higher investing player

in one pair has a strict incentive to form a link with the higher investing player in the other pair.

So consider connected networks. If only one player invests then it follows from optimality that this player must be investing 12 . If only two players are investing then it follows from arguments in Galeotti and Goyal (2010) that neither is investing 12. So they must be connected to each other. This implies from optimality of individual actions that each of them must access 
exactly 12 . Consider next the case that 3 players are investing. Again all of them must be investing strictly less than 12 . As everyone accesses 12 , each of them must access at least one other player. If a positive investing player accesses all three then the sum total investments must equal 12. So in the three investors case we have proved that the sum of investments must equal 12.

Finally, consider the case that all four players make positive investments. We first consider the case that a player with $x$ is a leaf. Observe that in this case there is a player with $y$ such that $x+y=12$, However, as the network is connected $y$ must have one other link with someone with investment $z$. So there is a player who accesses $x+y+z$, where all investments are positive. From optimality of individual investments it follows that $x+y+z=12$, but this is a contradiction. So no player is a leaf. Similarly, we can show that a network in which a player has three links must imply that this player accesses all investments, which must then be equal to 12 . So the only possibility left is that every player has two links. This means that the network is a ring. This means that all players must make equal investments and sum of three investments must equal 12. In other words, every player invests 4 . This is impossible if $k=24$ or $k=36$. If $k=10$, then each player is strictly better off cutting down own investment and linking with a new player. This completes the proof. QED

2. In Treatments IV-VI, in equilibrium all high-cost players choose 0 invest- 
ments.

Proof: The proof of connectedness is as in the previous result. So from now on we restrict attention to connected networks.

We go through the different cases with 1, 2, 3 and 4 contributors. Suppose there is 1 contributor. This contributor cannot be the high-cost $(\mathrm{H})$ player as he will choose 12 ; but then the low-cost (L) player will raise his investment to a positive amount so that total investment accessed is 13 .

Next consider the case of two contributors. If both players are high cost and contributing then neither can be contributing 12. But then it follows from optimality of individual behavior that the sum of investments must be 12. But then an L player will have a strict incentive to increase investment to 1 . So consider the case where one investor is $\mathrm{H}$ and the other is L. Again it follows that the sum must be 13 and both players must access each other. But then, the $\mathrm{H}$ player is accessing too much investment.

Consider next the case of 3 contributors. We need to separately consider the case of three $\mathrm{H}$ players, $2 \mathrm{H}$ players and $1 \mathrm{~L}$ player. Straightforward arguments exploiting the fact that an L player must access at least 13 and an active an $\mathrm{H}$ player must access exactly 12 imply imply that there is no equilibrium like that.

Finally, consider the case of 4 contributors. Here we follow the line of argument in the previous result. We start by showing that a player cannot be peripheral in an equilibrium network. We then consider networks in which no player is peripheral. Here we take up networks in which some player has 
3 links. If this is an $\mathrm{H}$ player then it contradicts the requirement that an $\mathrm{H}$ player must access exactly 12, while there is an L player who is accessing exactly 13. Similarly, if the L player has 3 links then we need to consider a range of networks with $3,4,5$ and 6 links and in each case we can use integer investments, and the requirement that the L player must access exactly 13 , while the $\mathrm{H}$ player accesses exactly 12 , to show that this cannot be sustained in equilibrium. This leaves only the case in which every player has exactly 2 links. In the ring network, it can be checked that we run afoul of integer constraints. So 4 contributors cannot be sustained in equilibrium. We are left with only one option: one contributor who is of the low-cost type. QED 
Proof of Observation: We start with incentives of the hub player.

- Adding a link to hub (or periphery) player: this would simply lower payoff by $k$ and is clearly unprofitable.

- Cutting a link to hub player: this can potentially raise payoffs by $k$.

- Increasing information acquisition: the hub player already accesses investments in excess $\hat{y}$. All other players are already connected to the hub. So an increase in investment can only lead to lower investments by others and thus lower utility.

- Reducing information acquisition: we know that lower investments than $\hat{y}-(m+1) k / c$ will mean that periphery players invest in excess of $k / c$ and this will lead to switches between self investment and links with other peripheral players, thus destroying the core-periphery network.

We next consider incentive of the periphery player:

- Severing the link to hub: this will clearly reduce payoffs since $x_{i}>k / c$ and aggregate investments accessed by periphery player are $\hat{y}$.

- Adding a link to non-hub player: this is clearly unprofitable as $x_{j}<k / c$. It will also not raise investments of the new neighbor as this player will then accessing investments in excess of $\hat{y}$. 
- Reducing investments: this is unprofitable as total investments accessed are $\hat{y}$ and lower investment will not induce greater investment from current hub contacts. This was explained in the main text of the paper and defines the upper bound for $z$.

- Increasing investment: this is not by itself profitable as periphery player is accessing $\hat{y}$ in current profile. So the only incentive would be a link from a periphery player. However, such a link would lead to that new contact lowering investment to 0 . So again increasing investment cannot be profitable.

We now compute the bounds for $z$ for the different cost of linking and for the different core-periphery networks. The case with single hub has already been presented in the main text. We now complete the other cases, $k=24$ and $m=2$ : The bounds for $z$ are $-2.4<z<2.4$. So investment by a hub player is $x_{i}=4.8$ and by the periphery player is $x_{j}=2.4$. This means that aggregate investment is 14.4 .

Turning to the low cost case $k=10$. For $m=2$, we find the bounds for $z$ are $6<z<8$. The investment by the hub is $x_{i}=5$ and the investment by the peripheral player is $x_{j}=2$. This means that the aggregate investment is 14 . 


\section{Appendix B}

\begin{tabular}{|c|c|c|c|c|c|c|}
\hline Session & \multicolumn{5}{|c|}{ Treatments } \\
\hline 1 & $\begin{array}{c}\text { I } \\
(k=10, c=5)\end{array}$ & $\begin{array}{c}\text { II } \\
(k=24, c=5)\end{array}$ & $\begin{array}{c}\text { III } \\
(k=36, c=5)\end{array}$ & $\begin{array}{c}\text { IV } \\
\left(k=10, c_{i}=3\right)\end{array}$ & $\begin{array}{c}\text { V } \\
\left(k=24, c_{i}=3\right)\end{array}$ & $\left(k=36, c_{i}=3\right)$ \\
\hline 2 & III & II & I & VI & V & IV \\
& $(k=36, c=5)$ & $(k=24, c=5)$ & $(k=10, c=5)$ & $\left(k=36, c_{i}=3\right)$ & $\left(k=24, c_{i}=3\right)$ & $\left(k=10, c_{i}=3\right)$ \\
\hline 3 & IV & V & VI & I & II & III \\
& $\left(k=10, c_{i}=3\right)$ & $\left(k=24, c_{i}=3\right)$ & $\left(k=36, c_{i}=3\right)$ & $(k=10, c=5)$ & $(k=24, c=5)$ & $(k=36, c=5)$ \\
\hline 4 & VI & V & IV & III & II & I \\
& $\left(k=36, c_{i}=3\right)$ & $\left(k=24, c_{i}=3\right)$ & $\left(k=10, c_{i}=3\right)$ & $(k=36, c=5)$ & $(k=24, c=5)$ & $(k=10, c=5)$ \\
\hline 5 & I & II & III & IV & V & VI \\
& $(k=10, c=5)$ & $(k=24, c=5)$ & $(k=36, c=5)$ & $\left(k=10, c_{i}=3\right)$ & $\left(k=24, c_{i}=3\right)$ & $\left(k=36, c_{i}=3\right)$ \\
\hline 6 & III & II & I & VI & V & IV \\
& $(k=36, c=5)$ & $(k=24, c=5)$ & $(k=10, c=5)$ & $\left(k=36, c_{i}=3\right)$ & $\left(k=24, c_{i}=3\right)$ & $\left(k=10, c_{i}=3\right)$ \\
\hline 7 & IV & V & VI & I & II & III \\
& $\left(k=10, c_{i}=3\right)$ & $\left(k=24, c_{i}=3\right)$ & $\left(k=36, c_{i}=3\right)$ & $(k=10, c=5)$ & $(k=24, c=5)$ & $(k=36, c=5)$ \\
\hline 8 & VI & V & IV & III & II & I \\
& $\left(k=36, c_{i}=3\right)$ & $\left(k=24, c_{i}=3\right)$ & $\left(k=10, c_{i}=3\right)$ & $(k=36, c=5)$ & $(k=24, c=5)$ & $(k=10, c=5)$ \\
\hline
\end{tabular}

Table B.1: Sequence of treatments

\begin{tabular}{|c|c|c|c|c|c|}
\hline & $\begin{array}{c}\text { Model } 1 \\
\text { Baseline } \\
\text { Treatment I }\end{array}$ & $\begin{array}{c}\text { Model } 2 \\
\text { Treatment IV } \\
c_{i}=3, k=10\end{array}$ & $\begin{array}{c}\text { Model } 3 \\
\text { Homogeneous } \\
\text { Treatments I-III }\end{array}$ & $\begin{array}{c}\text { Model } 4 \\
\text { Heterogeneous } \\
\text { Treatments IV-VI }\end{array}$ & $\begin{array}{l}\text { Model } 5 \\
\text { Full } \\
\text { Sample }\end{array}$ \\
\hline in-degree & $1.367^{* * *}$ & $1.574^{* * *}$ & $1.316^{* * *}$ & $1.528^{* * *}$ & $1.413^{* * *}$ \\
\hline & [13.501] & [12.183] & [18.549] & [17.893] & [25.094] \\
\hline$k=10$ & & & $\begin{array}{c}-1.331^{* *} \\
{[-2.356]}\end{array}$ & $\begin{array}{l}-1.071^{*} \\
{[-1.764]}\end{array}$ & $\begin{array}{c}-0.717^{* *} \\
{[-2.021]}\end{array}$ \\
\hline$k=36$ & & & 0.119 & 0.461 & $0.769^{* *}$ \\
\hline Homogeneous costs & & & [0.209] & {$[0.781]$} & $\begin{array}{c}{[2.111]} \\
-0.095 \\
{[-0.753]}\end{array}$ \\
\hline Session dummies & yes & yes & yes & yes & yes \\
\hline Period dummies & yes & yes & yes & yes & yes \\
\hline Constant & $\begin{array}{c}1.646^{* * *} \\
{[3.647]}\end{array}$ & $\begin{array}{c}1.289^{* * *} \\
{[3.746]}\end{array}$ & $\begin{array}{c}3.984^{* * *} \\
{[5.816]}\end{array}$ & $\begin{array}{c}2.833^{* * *} \\
{[3.808]}\end{array}$ & $\begin{array}{c}3.351^{* * *} \\
{[11.404]}\end{array}$ \\
\hline No. observations & 456 & 456 & 1368 & 1368 & 2736 \\
\hline No. clusters & 114 & 114 & 342 & 342 & 684 \\
\hline$F$ & 15.261 & 13.090 & 16.953 & 16.467 & 26.872 \\
\hline$R^{2}$ (adj.) & 0.340 & 0.328 & 0.214 & 0.227 & 0.221 \\
\hline Prob $>F$ & 0.000 & 0.000 & 0.000 & 0.000 & 0.000 \\
\hline
\end{tabular}

Table reports t-values in square brackets; standard errors corrected

for intra-network correlation; period and session dummies incl. ${ }^{*} p<0.1,{ }^{* *} p<0.05,{ }^{* * *} p<0.01$.

Table B.2: OLS Regressions with Individual Investment as Dependent Variable, Treatments I - VI 


\begin{tabular}{|c|c|c|c|c|c|c|}
\hline & $\begin{array}{c}\text { Treatment I } \\
c=5, k=10\end{array}$ & $\begin{array}{l}\text { Treatment II } \\
c=5, k=24\end{array}$ & $\begin{array}{l}\text { Treatment III } \\
c=5, k=36\end{array}$ & $\begin{array}{l}\text { Treatment IV } \\
c_{i}=3, k=10\end{array}$ & $\begin{array}{c}\text { Treatment V } \\
c_{i}=3, k=24\end{array}$ & $\begin{array}{l}\text { Treatment VI } \\
c_{i}=3, k=36\end{array}$ \\
\hline \multicolumn{7}{|l|}{ Data } \\
\hline Equilibria & $\begin{array}{c}1 \\
(0.8 \%)\end{array}$ & $\begin{array}{c}4 \\
(3.4 \%)\end{array}$ & $\begin{array}{c}2 \\
(1.7 \%)\end{array}$ & $\begin{array}{c}2 \\
(1.7 \%)\end{array}$ & 0 & 0 \\
\hline $\begin{array}{l}\text { Equilibrium } \\
\text { structures }\end{array}$ & $\begin{array}{c}29 \\
(25.4 \%)\end{array}$ & $\begin{array}{c}34 \\
(29.7 \%)\end{array}$ & $\begin{array}{c}17 \\
(14.9 \%)\end{array}$ & $\begin{array}{c}5 \\
(4.4 \%)\end{array}$ & $\begin{array}{c}22 \\
(19.29 \%) \\
\end{array}$ & $\begin{array}{c}14 \\
(12.28 \%)\end{array}$ \\
\hline \multicolumn{7}{|l|}{ Chance } \\
\hline Equilibria & $\begin{array}{c}<0.01 \\
(<0.001 \%)\end{array}$ & $\begin{array}{c}<0.01 \\
(<0.001 \%)\end{array}$ & $\begin{array}{c}<0.01 \\
(<0.001 \%)\end{array}$ & $\begin{array}{c}<0.01 \\
(<0.001 \%)\end{array}$ & $\begin{array}{c}<0.01 \\
(<0.001 \%)\end{array}$ & $\begin{array}{c}<0.01 \\
(<0.001 \%)\end{array}$ \\
\hline $\begin{array}{l}\text { Equilibrium } \\
\text { structures }\end{array}$ & $\begin{array}{l}5.79 \\
(5 \%) \\
\end{array}$ & $\begin{array}{c}3.56 \\
(3.1 \%)\end{array}$ & $\begin{array}{c}1.78 \\
(1.5 \%)\end{array}$ & $\begin{array}{c}0.44 \\
(0.4 \%) \\
\end{array}$ & $\begin{array}{c}0.44 \\
(0.4 \%) \\
\end{array}$ & $\begin{array}{c}0.44 \\
(0.4 \%) \\
\end{array}$ \\
\hline Total & 114 & 114 & 114 & 114 & 114 & 114 \\
\hline
\end{tabular}

Table reports number of observations and \% of total (in parentheses).

The reported numbers for chance give the expected numbers of equilibria if players had chosen their strategies randomly.

Table B.3: Frequencies and Percentages of Equilibria and Equilibrium Structures 


\section{- Instructions -}

Please read the following instructions carefully. These instructions are equal for all the participants. The instructions state everything you need to know in order to participate in the experiment. If you have any questions, please raise your hand. One of the experimenters will approach you in order to answer your question.

You can earn money by means of earning points during the experiment. The number of points that you earn depends on your own choices and the choices of other participants. At the end of the experiment, the total number of points that you earn during the experiment will be exchanged at an exchange rate of:

\section{0 points $=1$ Euro}

The money you earn will be paid out in cash at the end of the experiment without other participants being able to see how much you earned. Further instructions on this will follow in due time. During the experiment you are not allowed to communicate with other participants. Turn off your mobile phone and put it in your bag. Also, you may only use the functions on the screen that are necessary to carry out the experiment. Thank you very much.

\section{- Overview of the experiment -}

The experiment consists of six scenarios. Each scenario consists again of one trial round and three paid rounds (altogether 24 rounds of which 18 are relevant for your earnings).

In all scenarios you will be grouped with three other randomly selected participants. At the beginning of each of the 24 rounds, the groups and the positions within the groups will be randomly changed. The participants that you are grouped with in one round are very likely different participants from those you will be grouped with in the next round. It will not be revealed with whom you were grouped at any moment during or after the experiment.

The participants in your group will be shown as circles on the screen (see Figure 1). You are displayed as a blue circle, while the other participants are displayed as black circles. You will be able to connect to one or more other participants in your group during each round. By clicking on one of the other participants, you become connected to this other participant. An arrow appears to indicate the connection. By clicking again on the participant the arrow and, thus, the connection is removed again. You are also connected to another participant if this other participant clicks once on you. The participant on whose side a one-sided arrow starts has initiated this connection and has to pay some points for this connection. If both participants have clicked for a specific connection a two-headed arrow appears and both participants need to pay points for this connection. All participants that are connected to you by any kind of arrow will be called your neighbors. Hence, in Figure 1 the participants with " 75 " and with " 118 " in their circles are your neighbors. 
Figure 1: Explanation of screen elements

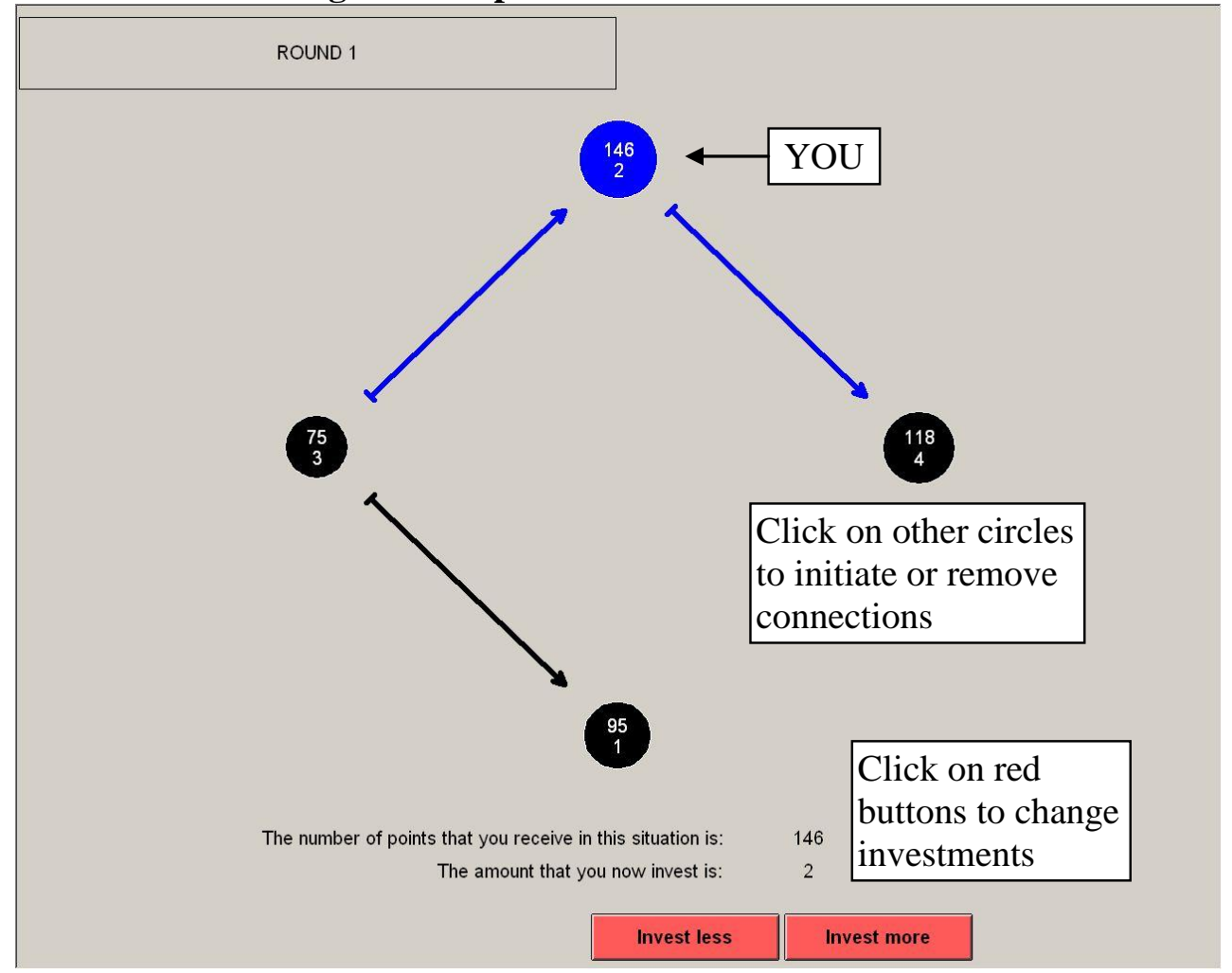

You can earn points in a round by investing, but investing also costs points. The points you receive in the end depend on your own investment and the investments of your neighbors. By clicking on one of the two buttons at the bottom of the screen you increase or decrease your investment. At the end of the round, you receive the amount of points that is shown on the screen at that moment in time. In other words, your final earnings only depend on the situation at the end of every round.

Each round lasts between 105 and 135 seconds. The end will be at an unknown and random moment in this time interval. Therefore, different rounds will not last equally long.

The points you will receive can be seen as the top number in your blue circle. The points others will receive are indicated as the top number in the black circles of others. Next to this, the size of the circles changes with the points that you and the other participants will receive: a larger circle means that the particular participant receives more points. The bottom number in the circles indicates the amount invested by that participant.

\section{$\underline{\text { Remarks: }}$}

- It can occur that there is a time-lag between your click and the changes of the numbers on the screen. One click is enough to change a connection or to change your investment by one unit. A subsequent click will not be effective before the previous click is effectuated.

- Therefore wait until a connection is changed or your investment is adapted before making further changes! 


\section{- Your earnings -}

Now we explain in detail how the number of points that you earn depends on the investments and the connections. Read this carefully. Do not worry if you find it difficult to grasp immediately. We also present an example with calculations below. Next to this, there is a trial round for each scenario to gain experience with how connections and investments affect your earnings.

In all scenarios, the points you receive at the end of each round depend in a similar way on two factors:

1. Every connection that you initiated yourself costs a given number of points (this will be either 10, 24 or 36).

2. Every unit that you invest yourself will cost you 5 points most of the time; in some scenarios, there is one participant in your group (maybe yourself) for whom every unit investment costs only 3 points. This participant will be displayed with an additional square around the circle (see Figure 3).

3. You earn points for each unit that you invest yourself and for each unit that your neighbors invest (the earnings related to a neighbor's investments do not depend on whether an arrow points toward yourself, toward the neighbor, or in both directions).

If you sum up all units of investment of yourself and your neighbors, the following table gives you the points that you earn from these investments:

\begin{tabular}{|l|c|c|c|c|c|c|c|c|c|c|c|}
\hline $\begin{array}{l}\text { Your investment plus } \\
\text { your neighbors' } \\
\text { investments }\end{array}$ & 0 & 1 & 2 & 3 & 4 & 5 & 6 & 7 & 8 & 9 & 10 \\
\hline Points & 0 & 28 & 54 & 78 & 100 & 120 & 138 & 154 & 168 & 180 & 190 \\
\hline
\end{tabular}

\begin{tabular}{|l|c|c|c|c|c|c|c|c|c|c|c|}
\hline $\begin{array}{l}\text { Your investment plus } \\
\text { your neighbors' } \\
\text { investments }\end{array}$ & 11 & 12 & 13 & 14 & 15 & 16 & 17 & 18 & 19 & 20 & 21 \\
\hline Points & 198 & 204 & 208 & 210 & 211 & 212 & 213 & 214 & 215 & 216 & 217 \\
\hline
\end{tabular}

The higher the total investments, the lower are the points earned from an additional unit of investment. Beyond an investment of 21, you earn one extra point for every additional unit invested by you or one of your neighbors.

Note: if your and your neighbors' investments add up to 12 or more, earnings increase by less than 5 points for each additional unit of investment. 
Suppose

\section{- Example shown in Figure 2 -}

1. initiating connections costs 24 points in this scenario;

2. you initiated one connection with one participant and one other participant initiated a connection with you;

3. you invested 2 units;

4. one of your neighbors invested 3 units and the other neighbor invested 4 units.

Then you have to pay 24 points for the connection you initiated and 2 times $5=10$ points for your own investments. Therefore, your total costs are 34 points.

The investments that you profit from are your own plus your neighbors' investments: 2 $+3+4=9$ (see bottom numbers in the circles from you and your neighbors on the right and on the left). In the table you can see that your earnings from this are 180 points.

In total, you would receive $180-34=146$ points if this would be the situation at the end of the round. Figure 2 shows this example as it would appear on the screen. The investment of the fourth participant in your group (at the bottom of the screen) does not affect your earnings. In the trial round before each scenario, you will have time to get used to how the points you receive change with investments.

The participant on the left has initiated two connections, invests in 3 units himself and profits from $3+2+1=6$ units in total. Therefore, this participant receives in this situation 138 (see table) $-2 \times 24-3 \times 5=75$ points.

\section{Figure 2: Numerical example}

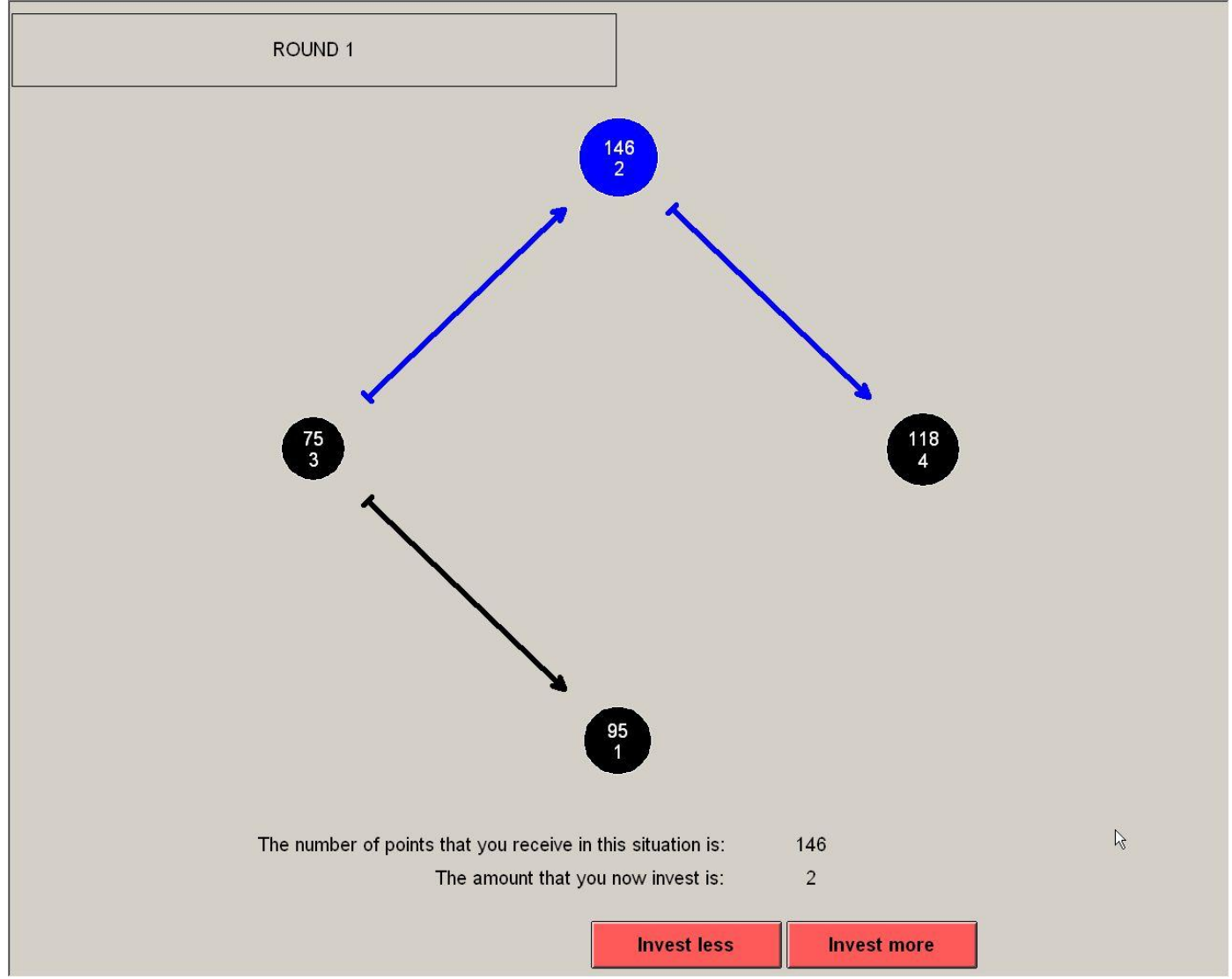




\section{- Scenarios -}

All rounds are basically the same. The things that change between scenarios are:

1. The costs for a connection will be 10,24 , or 36 points.

2. There might be one participant who pays only 3 points per unit of investment. This participant is marked with an additional square. In Figure 3, this is the participant on the left. This participant earns 6 points more than in Figure 2 because he pays $3 \times 2=6$ points less for his three units of investments, which brings his total earnings to $138-2 \times 24-3 \times 3=81$.

When a new scenario starts, you will get a message on the screen that describes the new scenario. Please read these messages carefully. As indicated before each scenario starts with a trial round. At the top of the screen you can also see when you are in a trial round. Paying rounds are indicated by "ROUND" while trial rounds are indicated by “TRIAL ROUND”.

\section{Figure 3: Second example}

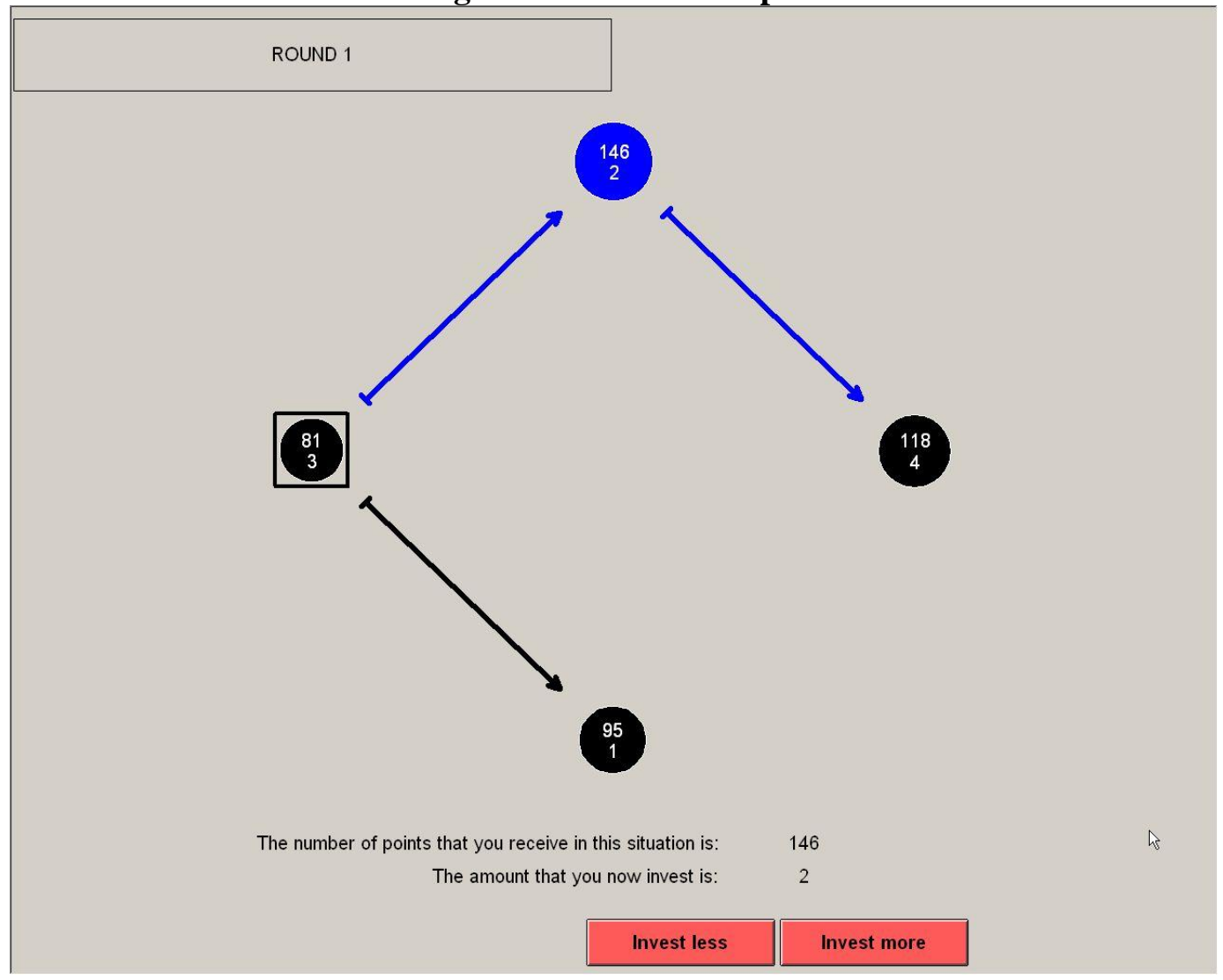

\section{- Questionnaire -}

After the 24 rounds you will be asked to fill in a questionnaire. Please take your time to fill in this questionnaire accurately. In the mean time your earnings will be counted. Please remain seated until the payment has taken place. 